\title{
Design, Synthesis, and Preclinical Bio Evaluation of Chemical Conjugates Derived from Phytophenols and Nitrobenzoate as First Plausible Inhibitors of MPO Useful in CVD Treatment
}

\author{
Premkumar Jayaraj ${ }^{1}$ (D), Rajagopal Desikan ${ }^{1, *}$ * \\ 1 Department of Chemistry, School of Advanced Science, Vellore Institute of Technology, Vellore-632014, India \\ * Correspondence: desikanrajagopal@gmail.com;
}

Scopus Author ID 36522441900

Received: 18.11.2020; Revised: 12.12.2020; Accepted: 14.12.2020; Published: 16.12.2020

\begin{abstract}
Phytophenols are important phytonutrients and useful building blocks for medicinal chemistry research. Designed conjugates derived from phytophenols and nitrobenzoate were evaluated for MPO inhibition using in-silico docking and ADMET studies. Hit to lead compounds were prepared and confirmed by NMR, mass, and single-crystal XRD analysis. Based on the in-silico study, an invitro MPO inhibition assay was performed and identified two best compounds 1 and 2 (MPO-IC50 value is 12.88 and $14.97 \mu \mathrm{M}$ respectively) lead molecules. An ex-vivo anti-inflammatory study was performed with human erythrocyte hemolysis using coagulated blood cells with increasing concentration (20 to $100 \mu \mathrm{M}$ ) of the lead molecules. The activity range was found to be $\sim 85 \%$ and 75\% for compounds 1 and 2, respectively. DPPH and ABTS radical scavenging assays of the lead molecules were compared with ascorbic acid (positive control). MTT-cell line study shows that lead compounds were non-toxic even at higher concentrations. The outcome of this study demonstrated that conjugates 1 and 2 be considered potent inhibitors of MPO and useful cardiovascular therapeutic agents.
\end{abstract}

Keywords: phytophenol scaffolds; molecular docking; myeloperoxidase inhibitor; cardiovascular disease; atherosclerosis.

(C) 2020 by the authors. This article is an open-access article distributed under the terms and conditions of the Creative Commons Attribution (CC BY) license (https://creativecommons.org/licenses/by/4.0/).

\section{Introduction}

In medicinal chemistry research, small molecules have an authoritative role in offering bio-activity toward various disease targets $[1,2,3,4]$. In drug design and discovery platforms, some small molecules with heterocyclic structures are extremely useful for targeted diseases. However, they are unsafe due to potential toxicity associated with molecular fragments within the bio environment, causing the off-target effect. In recent decades, phytonutrients can offer a solution to eliminating molecular toxicity with high efficacy toward a specific target with a lesser dosage [5,6]. Table 1 shows phytochemicals and their biological utilities such as antioxidant, anti-inflammatory agents, useful agents for treating cardiovascular disease (CVD), cancer, neurovascular, and diabetes. They belong to a class of naturally available phytochemicals with a diverse biochemical application. Also, drugs with nitrobenzene entity are useful to treat various diseases. The presence of nitrobenzene structure within the designed drug entities might offer benefits to the drug molecules' overall efficacy. Some commercially available drugs with nitrobenzene unit and its usefulness in treating various conditions are; 
Nifedipine (treat high blood pressure and myocardial ischemia), Aranidipine (Calcium channels blocker), Cilnidipine (Anti-hypertensive drug), Lercanidipine (prevent heart disease, heart attacks, and strokes), Flutamide (treatment for prostate cancer), Azathioprine (rheumatoid arthritis), Tolcapone (Parkinson's disease), Chloramphenicol (antibiotic), and Nitrazepam (insomnia). CVD is a predominant reason for mortality and morbidity globally due to tobacco, unhealthy diet, and excessive alcohol use. Inflammation is a part of the immune response to an illness or injury. An accumulation of oxidized lipid in the artery wall at the inflammation site can manifest into atherosclerotic plaque. Inflammation is shown to have a strong link in the manifestation of CVD. Uncontrolled building up of the plaque can cause heart attack and stroke. The oxidative enzyme, myeloperoxidase (MPO) heme protein, is known to cause inflammation through free radical-mediated oxidation of proteins and lipids.

MPO is a heme protein responsible for the manifestation of atherosclerosis and other CVD complications [7, 8]. MPO is known to involve in oxidizing lipoproteins such as LDL (low-density lipoprotein) and HDL (high-density lipoprotein) [9, 10]. These oxidized lipids trigger a physiological reaction that will induce a cascading effect in atherosclerotic plaque formation in the arteries. This leads to several CVD complications, predominantly assisted by inflammatory pathways $[11,12]$. Oxidized LDL (Ox-LDL) was known to cause artery block by way of atherosclerotic plaque burden. HDL's functional role is to help recycle LDL or HDLassisted modification and protect the artery wall against excessive deposition of fatty steak. At the MPO generation site, MPO-assisted oxidants can oxidize both LDL and HDL and make them dysfunctional. Ox-LDL is transformed into foam cells and then to fatty-like deposition on the endothelium. Oxidized HDL (Ox-HDL) loses its functionality to behave as a mediator in the Reverse Cholesterol Transfer (RCT) pathway [13].

Table 1. Functional utilities of phytochemicals for various diseases.

\begin{tabular}{l|l|l|l} 
S.No & Phytochemicals & Target & Reference \\
\hline 1 & Caffeine & Central nerve system $(\mathrm{CNS})$ & {$[14]$} \\
\hline 2 & Beta-carotene & Anti-cancer, Skin protections & {$[15,16]$} \\
\hline 3 & Quercetin & Diabetes, Anti-inflammatory & {$[17,18]$} \\
\hline 4 & Sesamol & Cardio protective nutrient & {$[12,19,20,21]$} \\
\hline 5 & Coumarin & Anti-tumour & {$[22,23]$} \\
\hline 6 & Ferulic acid & Oxidative stress & {$[24,25]$} \\
\hline 7 & Apocynin & Atherosclerotic, Neuroprotective & {$[26,27]$} \\
\hline 8 & Resveratrol & Neuroprotection & {$[28]$} \\
\hline 9 & Lipoic acid & Neuroprotection, atherosclerosis & {$[27,29]$} \\
\hline 10 & Captopril & Neurovascular protective agent & {$[30]$} \\
\hline 11 & Scopoletin & Blood pressure-lowering & {$[31,32]$}
\end{tabular}

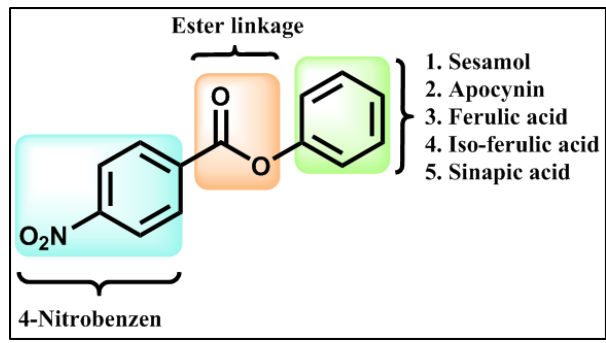

Figure 1. General structure of the designed compounds.

Next, we have designed chemical conjugates derived from natural phytophenols with nitrobenzoate. The general design of the structure was given in Figure 1. After predicting insilico ADMET (Absorption Distribution Metabolism Excretion Toxicity) parameters, we have turned our attention toward molecular docking study. Next, the designed molecules were 
synthesized and characterized using NMR, IR, mass spectroscopic techniques. Additionally, single crystal-XRD data of one selected structure revealed the crystallographic pattern of the molecule. In vitro enzyme assays were used to fully assess the bio-efficacy of the molecules aimed at the MPO target. These results demonstrated that the proposed entities are versatile chemical conjugates derived from nature-based safe entities useful for atherosclerotic CVD treatment.

\section{Materials and Methods}

All starting materials, protein, and reagents were purchased from Sigma-Aldrich Chemicals India; Solvents were purchased from SD Fine chemicals. Molecular docking was performed using AutoDockTool-1.5.6, and the pkCSM database was used to validate ADMET parameters.

\subsection{In silico studies.}

i) Drug likeness: Assessment on the drug-likeness of designed phytophenol for compounds concerning the Lipinski's rule was predicted using ChemDraw Professional 15.0 to enhance the success rate of developing MPO inhibitor for advanced preclinical development useful in CVD treatment. The evaluation of HBD (Hydrogen Bond Donor) and HBA (Hydrogen Bond Acceptor) collections and other physicochemical parameters were identified by using in silico studies [33, 34].

ii) Pharmacokinetics properties prediction: Pharmacokinetics of the designed compounds were evaluated by using the pkCSM web server database. This method was used to predict the ADMET parameters for the designed compounds [35].

iii) Molecular docking: An AutoDock-1.5.6 docking tool was employed for molecular modeling studies $[36,37]$ using MPO-heme protein complex downloaded from the RCSB-PDB (Protein Data Bank - https://www.rcsb.org) with crystal structure PDB ID: 5FIW. The original $\mathrm{X}$-ray crystal structure resolution is $1.7 \AA$. This protein was employed as an input structure for protein preparation. Hydrogen atoms were added to the MPO followed by the addition of Gasteiger and Kollman charges. It may be noted that the PDB entry did not contain any crystallographic water molecules in the MPO-heme protein complex. The ligands were drawn using Chemdraw-3D-15.0, and the grid box was prepared to cover active site residues. The analyzed protein-ligand complex was visualized using Discovery Studio Visualizer-2019, and the images were taken in $2 \mathrm{D}$ and $3 \mathrm{D}$ format.

\subsection{Chemical synthesis.}

\subsubsection{Synthesis of phytophenol derivatives by method-1.}

\subsubsection{General Procedure.}

A reaction flask containing 4-nitrobezoic acid (167 $\mathrm{mg}, 1 \mathrm{mmole})$ and alcohol substituents $(1 \mathrm{mmol})$ in $15 \mathrm{ml}$ of anhydrous dichloromethane in presence of dimethyl amino pyridine ( $2 \mathrm{mmol}, 244 \mathrm{mg}$ ). The reaction was carried out at room temperature under a nitrogen atmosphere. To this, N-(3-dimethylaminopropyl)-N'-ethyl carbodiimide hydrochloride (2 mmol, $310 \mathrm{mg}$ ) was added for 45 minutes, and the whole mixture was allowed to stir at room temperature (RT) for $12 \mathrm{~h}$. The thin layer chromatography was utilized to monitor the progress of the reaction. At the end of the reaction, the mixture was extracted with dichloromethane. 
The organic phase was washed with brine solution and dried over anhydrous $\mathrm{MgSO}_{4}$. The organic layer was concentrated, and the crude reaction mixture was purified on column chromatography.

\subsubsection{Synthesis of phytophenol derivatives by method-2.}

Compound 1: The solution of sesamol ( $1 \mathrm{mmol}, 0.138 \mathrm{~g})$, and 4-nitrobenzoyl chloride $(1 \mathrm{mmol}, 0.185 \mathrm{~g})$ in $15 \mathrm{~mL}$ of anhydrous dichloromethane followed by the addition of a base, triethylamine (5 drops) and the reaction was carried in a nitrogen atmosphere. Further, the reaction blend was allowed to stir at RT for 3 hours. The conversion of reactants into a product was observed by thin-layer chromatography (TLC). The reaction blend was extracted with dichloromethane, treated with brine solution, and dried over anhydrous Magnesium sulfate $\left(\mathrm{MgSO}_{4}\right)$ followed by organic solvent was evaporated under reduced pressure. Scheme-1 shows the synthesis of designed compounds. The resultant crude compound 1 was purified on column chromatography; the yield was achieved by $89 \%$ yellowish green solid. ${ }^{1} \mathrm{H}$ NMR 400 $\mathrm{MHz}_{\mathrm{CDCl}}: \delta 8.36(\mathrm{~s}, 4 \mathrm{H}), 6.84(\mathrm{~d}, \mathrm{~J}=8.36 \mathrm{~Hz}, 1 \mathrm{H}), 6.75(\mathrm{~d}, \mathrm{~J}=2.32 \mathrm{~Hz}, 1 \mathrm{H}), 6.67(\mathrm{dd}, \mathrm{J}=$ 2.36, 8.36 Hz, 1H), 6.03 (s, 2H), ppm. ${ }^{13} \mathrm{C}$ NMR $100 \mathrm{MHz}: \delta 163.63,150.90,148.23,145.83$, 144.73, 134.85, 131.31, 123.74, 113.85, 108.16, 103.57, 101.92, ppm. LC-MS/MS: Calculated mass [M+1]: 288.0429, Obtained mass [M+1]: 288.0194 .

Compound 2: Compound-2 was synthesized by coupling of apocynin and 4nitrobenzoyl chloride as above mentioned facile methodology performed for compound 1 , yield was achieved with $93 \%$ white colour solid. ${ }^{1} \mathrm{H}$ NMR $400 \mathrm{MHz}, \mathrm{CDCl}_{3}$ : $\delta 8.38$ (t, J = $10.24 \mathrm{~Hz}, 4 \mathrm{H}), 7.67$ (s, 1H), 7.63 (d, J = 8.20 Hz, 1H), 7.27 (s, 1H), 3.89 (s, 3H), 2.64 (s, 3H), ppm. ${ }^{13} \mathrm{C}$ NMR $100 \mathrm{MHz}: \delta$ 196.90, 162.45, 151.33, 151.00, 143.48, 136.41, 134.37, 131.51, 123.76, 122.68, 122.00, 113.76, 111.61, 109.70, 56.12, 26.59, ppm. LC-MS/MS: Calculated mass $[\mathrm{M}+1]$ : 316.0742 , Obtained mass [M+1]: 316.0495 .

Compound 3: Compound-3 was synthesized by couple of ferulic ester (Ferulic ester was synthesized from ferulic acid by esterification method) and 4-nitrobenzoyl chloride as above mentioned facile methodology performed for compound 1, yield was achieved with $86 \%$ light yellow solid. ${ }^{1} \mathrm{H}$ NMR $400 \mathrm{MHz}, \mathrm{CDCl}_{3}: \delta 8.37$ (dd, J = 9.20, $\left.12.68 \mathrm{~Hz}, 4 \mathrm{H}\right), 7.69(\mathrm{~d}, \mathrm{~J}=$ $16.00 \mathrm{~Hz}, 1 \mathrm{H}), 7.18$ (d, J = 11.68 Hz, 3H), 6.43 (d, J = $15.97 \mathrm{~Hz}, 1 \mathrm{H}), 3.86$ (s, 3H), 3.82 (s, $3 \mathrm{H})$, ppm. ${ }^{13} \mathrm{C}$ NMR $100 \mathrm{MHz}: \delta$ 162.4, 157.91, 146.59, 146.22, 139.19, 136.37, 129.80, 129.16, 126.71, 126.25, 118.96, 118.70, 118.36, 116.46, 113.70, 106.70, 51.22, 47.05, ppm. LC-MS/MS: Calculated mass [M+1]: 358.0848, Obtained mass [M+1]: 358.0583.

Compound 4: Compound-4 was synthesized by iso-ferulic ester (Iso-ferulic ester was synthesized from iso-ferulic acid by esterification method) and 4-nitrobenzoyl chloride above mentioned facile methodology as performed for compound 1, yield was achieved with $88 \%$ white colour solid. ${ }^{1} \mathrm{H}$ NMR $400 \mathrm{MHz}, \mathrm{CDCl}_{3}: \delta 8.38(\mathrm{dd}, \mathrm{J}=9.08,11.92 \mathrm{~Hz}, 4 \mathrm{H}), 7.64(\mathrm{~d}, \mathrm{~J}$ $=15.88 \mathrm{~Hz}, 1 \mathrm{H}), 7.45(\mathrm{~d}, \mathrm{~J}=8.52 \mathrm{~Hz}, 1 \mathrm{H}), 7.39(\mathrm{~s}, 1 \mathrm{H}), 7.04(\mathrm{~d}, \mathrm{~J}=8.52 \mathrm{~Hz}, 1 \mathrm{H}), 6.33(\mathrm{~d}, \mathrm{~J}=$ $15.92 \mathrm{~Hz}, 1 \mathrm{H}), 3.86$ (s, 3H), 3.80 (s, 3H), ppm. ${ }^{13} \mathrm{C}$ NMR $100 \mathrm{MHz}: \delta 167.43,162.73,152.72$, 150.94, 143.45, 139.77, 134.52, 131.48, 128.16, 127.70, 123.74, 121.78, 116.70, 112.53, 56.10, 51.74, ppm. LC-MS/MS: Calculated mass [M+1]: 380.0745, Obtained mass [M+1]: 380.0349. Compound 5: Compound-5 was synthesized by sinapic ester (sinapic ester was synthesized from sinapic acid by esterification method), and 4-nitrobenzoyl chloride above mentioned facile methodology as performed for compound 1, the yield was achieved with $88 \%$ white color solid. ${ }^{1} \mathrm{H}$ NMR $400 \mathrm{MHz}, \mathrm{CDCl}_{3}: \delta 8.38(\mathrm{dd}, \mathrm{J}=9.00,20.16 \mathrm{~Hz}, 4 \mathrm{H}), 7.66(\mathrm{~d}, \mathrm{~J}=15.92 \mathrm{~Hz}$, 
1H), $6.82(\mathrm{~s}, 1 \mathrm{H}), 6.43$ (d, J = $15.92 \mathrm{~Hz}, 1 \mathrm{H}), 3.85$ (s, 6H), 3.83 (s, 3H), ppm. LC-MS/MS: Calculated mass [M+1]: 388.0954, Obtained mass [M+1]: 388.0671.

For all the synthetic compounds NMR and LC-MS/MS data images were available in Supplementary information, Fig. S1 to Fig. S14.

\subsection{In vitro MPO inhibition assay.}

MPO inhibition assay was performed based on the literature report [38] using cell-free MPO protein and TMB (Tetramethylbenzidine) as an enzyme-substrate. Salicylhydroxamic acid, a known MPO inhibitor (positive control), was used. Other MPO co-substrates such as hydrogen peroxidase $\left(\mathrm{H}_{2} \mathrm{O}_{2}\right)$ and sodium chloride were also used. With variable concentrations, synthetic compounds were incubated at $37^{\circ} \mathrm{C}$ for an hour, incubated samples were read by fixed wavelength $(650 \mathrm{~nm})$. With the help of a dose-response curve, the $\mathrm{IC}_{50}$ values have been determined.

\subsection{Ex vivo anti-inflammatory activity.}

Alsever's solution was prepared using the following substrates; sodium citrate $(0.4 \mathrm{~g}$, $1.3 \mathrm{mmol})$, dextrose $(1 \mathrm{~g}, 5.5 \mathrm{mmol})$, citric acid $(0.025 \mathrm{~g}, 0.01 \mathrm{mmol})$, and sodium chloride $(0.21 \mathrm{~g}, 3.5 \mathrm{mmol})$ in $50 \mathrm{~mL}$ of distilled water. Blood was freshly collected from a consented healthy donor in ethylenediamine tetraacetic acid (EDTA) tubes. The sample was centrifuged at $3000 \mathrm{rpm}$ for 30 minutes, and supernatant (plasma and leucocytes) was carefully removed. Red blood cells $(5 \mathrm{~mL})$ were mixed with $5 \mathrm{~mL}$ of already prepared Alsever's reagent. The mixture was centrifuged at $3000 \mathrm{rpm}$ for 15 minutes. Next, the coagulated blood cells were separated and thoroughly washed with isosaline $(0.85 \% \mathrm{pH}-7.3)$; the processes of centrifuging and washing was repeated several times until the supernatant is clear. The efficacy of synthesized phytophenols for anti-inflammatory activity was tested by induced human erythrocyte hemolysis using coagulated blood cells. Different concentrations (20 to $100 \mu \mathrm{M}$ ) of the synthetic compound with RBC (red blood cell) erythrocyte blood cells $(100 \mu \mathrm{L})$ were prepared. Then, $5 \mathrm{~mL}$ of hypotonic $\left(10 \mathrm{mM}\right.$ Trisodium phosphate $\left(\mathrm{Na}_{3} \mathrm{PO}_{4}\right)$ comprising $5 \mathrm{mM}$ sodium chloride $(\mathrm{NaCl})$ ) buffer mixture was added to it. A synthetic compound containing blood cells and the hypotonic solutions were incubated for 10 minutes at $\sim 28{ }^{\circ} \mathrm{C}(\mathrm{RT})$. At the end of the incubation period, the mixture was centrifuged for 10-12 min at $3000 \mathrm{rpm}$. The top layer (supernatant) solution was separated and measure the absorbance at $560 \mathrm{~nm}$ using a UVvisible spectrophotometer [39].

\subsection{In vitro antioxidant assay.}

Briefly, $0.1 \mathrm{mM}$ solution of DPPH (2,2-diphenyl-1-picrylhydrazyl) in $\mathrm{CH}_{3} \mathrm{OH}$ was prepared, and $1 \mathrm{~mL}$ of this mixture was added to $3 \mathrm{~mL}$ of the solution of the synthetic compound at different concentration $(20,40,60,80$, and $100 \mu \mathrm{M})$. After vigorous mixing and standing at RT for 30 min., the absorbance was measured at $517 \mathrm{~nm}$. By spectroscopically monitoring the color change will provide a clue on antioxidant properties of the drug. A similar study was performed using ABTS (2,2'-azino-bis(3-ethylbenzothiazoline-6-sulfonic acid)) method of antioxidant study to scavenge ABTS + radical cation to identify antioxidant potentials of the drugs. Briefly, $7 \mathrm{mM}$ ABTS in water and $2.45 \mathrm{mM}$ potassium persulfate $(1: 1)$ were thoroughly mixed to generate ABTS + cation radical. Due to its photosensitive nature, this radical species is stored in RT's dark surroundings for 12-16 h before use. This radical 
cation solution was diluted with $\mathrm{CH}_{3} \mathrm{OH}$ to get an absorbance at $734 \mathrm{~nm}$. After adding compounds at different concentrations $(20,40,60,80$, and $100 \mu \mathrm{M})$ to a required volume of diluted ABTS + solution, the absorbance was measured after 30 minutes of initial mixing. To nullify the solvent effect, an appropriate blank solvent was measured in each assay. To compare the efficiency, ascorbic acid was used as a positive control. Measurement was also performed without inhibitor [40, 41].

\subsection{Cell viability assay.}

MTT ((3-(4,5-Dimethylthiazol-2-yl)-2,5-Diphenyltetrazolium Bromide)) assay was utilized to analyze the percentage of cell viability for the Phyto phenol compound; this cell viability results helped to find out the toxicity of the compound. This assay was carryout using RAW macrophage cells (RAW 264.7) with different concentrations of the Phytophenol compound $(20,40,60,80$, and $100 \mu \mathrm{M})$, and the results were corroborated with control. The method was adopted from the previous publication of our collaborator [42].

\section{Results and Discussion}

\subsection{Drug likeness.}

Rational designing of cardiovascular therapeutics utilizing simple computational tools is a powerful method to identify therapeutic agents within a reasonable timeframe. In line with this approach, we have invoked a rational approach to identifying lead molecules from various chemical structures. The outcome of the drug-likeness studies revealed that designed compounds 1 to 5 satisfied the Lipinski rule.

Compound 1 to 5 possess required MW of less than $500 \mathrm{amu}$, number of hydrogen bond acceptor (-N-, -O-, etc.,) of less than 10, number of hydrogen bond donor (-NH-, -OH-, etc.,) of less than 5 and NRB of 10. Also, Log $\mathrm{P}$ o/w, the aqueous solubility of the compound ( $\log$ S) should be less than 5, and calculations for TPSA based fragments were analyzed. All the estimated parameters of physicochemical properties were represented in Table 2. Based on these in-silico predicted parameters, designed compounds are suitable for further advancement in the drug development process supported by Lipinski properties.

Table 2. Functional utilities of phytochemicals for various diseases.

\begin{tabular}{l|l|l|l|l|l|l|l|l}
$\begin{array}{c}\text { Designed a compound } \\
\text { structure }\end{array}$ & HBA & HBD & NRB & Log Po/w & Log S & TPSA & MW & LV \\
\hline & 6 & 0 & 3 & 2.08 & 4.25 & 96.57 & 287.04 & 0 \\
\hline & & & & & & & & \\
\hline \\
\hline
\end{tabular}

* HBA: hydrogen bond acceptor; HBD: hydrogen bond donor; NRB: number of rotatable bonds; Log $\mathrm{P}_{\mathrm{O} / \mathrm{w}}$ : logarithmic partition coefficient of n-octanol and water; TPSA: topological polar surface area; MW: molecular weight; LV: Lipinski violations. 
The predicted parameters are all well within the acceptable range. Therefore designed compounds have satisfied the Lipinski properties with zero LV. This rule is designed to improve drug development's success rate from a preclinical stage to an advanced drug candidate. Any deviation in the Lipinski rule (molecular mass $>500$, HBD \& HBD, $>10 \& 5$, and the NRB have $>10$, follow the solubility level is $>5$ ) might have less success rate to be developed as a drug candidate for any target.

The presence of "in domain" for designed compounds indicates scope for further refinement within the structural domain. If compounds violate anyone or all the Lipinski rule, we assign compound(s) as "out of domain". Since designed compounds are referred to as "in domain", there is a space for further modification within the proposed structures to create additional chemical entities with better bio-activity.

\subsection{Pharmacokinetics properties prediction.}

pkCSM web server database is used to pre-assess the validation of ADMET parameters of designed compounds. The parameter values of the designed compounds are provided in Table 3. We concluded that these compounds have an acceptable level of absorption and distribution values based on the predicted parameters. Cytochrome P450 is the family of isozyme, which is mainly involved in the drug's metabolite processes. In $90 \%$ of the drug's metabolite, only six cytochromes such as CYP1A2, CYP2C19, CYP2C9, CYP2D6, CYP2E1, and CYP3A4 are involved. This DDI happens when the listed biomolecules have inhibited or induced by the drug. This DDI leads to adverse effects, or it may reduce the therapeutic efficacy of the drug.

In the present study, the ADMET predictions reveal the mixed role exhibited by the designed compounds either as inhibitors or induce. The data on DDI with five (CYP1A2, CYP2C19, CYP2C9, CYP2D6, CYP3A4) biomolecules revealed the expected line of predictions of chemical compounds, indicating that it may provide a balanced interaction within the bio-environment. This result is also discussed based on the in-silico prediction. It may slightly deviate when it is performed under actual in vitro studies. The change in reactivity pattern between computer predicted results and the actual outcome is well known in the literature for many available drugs in the market [43, 44].

The excretion of the drug was determined by renal OCT2 substrate. This OCT2 is shown to provide a prominent part in the drug's disposition and clearance, and OCT2 substrate has the potential role for adverse interactions with co-administered OCT2 inhibitors. Based on the results, it is presumed that the designed molecules are not a renal OCT2 substrate. The toxicity of the designed compounds was analyzed differently in silico analysis; the resulting designed compounds are either non-toxic or acceptable level of toxicity. Overall, the described ADMET parameters are comparable with a known anti-inflammatory medicament (aspirin). Based on these comparisons, we firmly believe that these molecules can exert action in modulating ADMET properties. This facilitates further refinement towards in silico and in vitro assays for the designed compounds.

\subsection{Molecular docking studies.}

The designed compounds were subjected to molecular docking interactions with MPO within the possible active site of the protein (PDB code: 5FIW) [36]. 
Table 3. In silico ADMET parameters for the designed compounds 1 to 5.

\begin{tabular}{|c|c|c|c|c|c|c|c|c|c|c|}
\hline \multicolumn{11}{|c|}{ Absorption } \\
\hline Com & $\begin{array}{c}\text { Ws } \\
(\log \\
\mathrm{mol} / \mathrm{L})\end{array}$ & \multicolumn{3}{|c|}{$\begin{array}{c}\text { CaCo2-P } \\
\left(\log \text { in } 10^{-6} \mathrm{~cm} / \mathrm{s}\right)\end{array}$} & $\begin{array}{c}\text { IA-h } \\
(\% \mathbf{A}) \\
(\log -\mathrm{Kp})\end{array}$ & SP & \multicolumn{2}{|c|}{ P-gs } & P-gI i & P-gII i \\
\hline 1 & -4.433 & \multicolumn{3}{|c|}{0.93} & 95.474 & -2.663 & \multicolumn{2}{|c|}{ No } & No & No \\
\hline 2 & -4.947 & \multicolumn{3}{|c|}{0.923} & 95.001 & -2.564 & \multicolumn{2}{|c|}{ No } & Yes & No \\
\hline 3 & -5.562 & \multicolumn{3}{|c|}{1.213} & 96.635 & -2.713 & \multicolumn{2}{|c|}{ No } & Yes & No \\
\hline 4 & -5.457 & \multicolumn{3}{|c|}{1.193} & 96.823 & -2.72 & \multicolumn{2}{|c|}{ No } & Yes & No \\
\hline 5 & -5.666 & \multicolumn{3}{|c|}{1.255} & 97.146 & -2.739 & \multicolumn{2}{|c|}{ No } & Yes & Yes \\
\hline \multicolumn{11}{|c|}{ Distribution } \\
\hline Com & \multicolumn{3}{|c|}{ VDss (log L/kg) } & FU- h & BBB-P & \multicolumn{5}{|c|}{ CNS-P } \\
\hline 1 & \multicolumn{3}{|c|}{-0.245} & 0.02 & -0.773 & \multicolumn{5}{|c|}{-2.355} \\
\hline 2 & \multicolumn{3}{|c|}{-0.198} & 0.05 & -0.844 & \multicolumn{5}{|c|}{-2.392} \\
\hline 3 & \multicolumn{3}{|c|}{-0.6} & 0 & -1.0 & \multicolumn{5}{|c|}{-2.511} \\
\hline 4 & \multicolumn{3}{|c|}{-0.610} & 0 & -1.016 & \multicolumn{5}{|c|}{-2.547} \\
\hline 5 & \multicolumn{3}{|c|}{0.885} & 0 & -1.218 & \multicolumn{5}{|c|}{-3.102} \\
\hline & & & & & Metabc & & & & & \\
\hline Com & $\begin{array}{l}\text { CYP2 } \\
\text { D6-S }\end{array}$ & CYP3A4-S & & CYP1A2 & & P2C19-i & $\begin{array}{c}\text { CYP2 } \\
\text { C9-i }\end{array}$ & CYI & 2D6-i & CYP3A4-i \\
\hline 1 & No & Yes & & Yes & & Yes & Yes & & To & Yes \\
\hline 2 & No & Yes & & Yes & & Yes & Yes & & To & No \\
\hline 3 & No & Yes & & Yes & & Yes & Yes & & To & Yes \\
\hline 4 & No & Yes & & No & & Yes & Yes & & To & $\mathrm{No}$ \\
\hline 5 & No & Yes & & No & & Yes & Yes & & To & Yes \\
\hline & & & & & Excre & & & & & \\
\hline Com & Total & Clearance (lo & $\mathrm{ml} / \mathrm{n}$ & in/kg) & & ReI & OCT2 st & ostrate & & \\
\hline 1 & & 0.542 & & & & & No & & & \\
\hline 2 & & 0.686 & & & & & No & & & \\
\hline 3 & & 0.711 & & & & & No & & & \\
\hline 4 & & 0.735 & & & & & No & & & \\
\hline 5 & & 0.921 & & & & & No & & & \\
\hline & & & & & Toxic & & & & & \\
\hline Com & $\begin{array}{l}\text { AME- } \\
\mathbf{T}\end{array}$ & $\begin{array}{l}\text { MTD(log } \\
\mathrm{mg} / \mathrm{kg} / \mathrm{D})\end{array}$ & $\begin{array}{c}\text { Her } \\
\text { g - } \\
\text { Ii }\end{array}$ & $\begin{array}{l}\text { Herg } \\
\text {-IIi }\end{array}$ & $\begin{array}{c}\text { ORAT } \\
\left(\mathrm{LD}_{50}\right) \\
(\mathrm{mol} / \mathrm{kg})\end{array}$ & $\begin{array}{c}\text { ORCT } \\
\text { (LOAEL) } \\
(\text { log- } \\
\text { mg/kg/D) }\end{array}$ & HT & SS & $\begin{array}{c}T p-\mathrm{T} \\
(\log \\
\mu \mathrm{g} / \mathrm{L})\end{array}$ & $\begin{array}{c}\text { MT }(\log / \mathrm{m} \\
\text { M) }\end{array}$ \\
\hline 1 & Yes & -0.21 & $\mathrm{No}$ & No & 2.352 & 1.356 & No & No & 0.746 & 0.092 \\
\hline 2 & Yes & 0.038 & No & No & 2.366 & 1.349 & Yes & No & 1.01 & 0.043 \\
\hline 3 & Yes & 0.148 & $\mathrm{No}$ & $\mathrm{No}$ & 2.586 & 2.047 & Yes & No & 0.577 & -0.869 \\
\hline 4 & Yes & 0.202 & No & No & 2.328 & 2.081 & Yes & No & 0.449 & -0.861 \\
\hline 5 & Yes & 0.423 & No & No & 2.518 & 2.134 & Yes & No & 0.329 & -1.205 \\
\hline
\end{tabular}

* Com - Compound; Ws - Water solubility; Caco2-P - Caco2-Permeability; IA-h - Intestinal absorption (human); SP - Skin Permeability; P-gs - P-glycoprotein substrate; P-gIi - P-glycoprotein I inhibitor; P-gIIi - P-glycoprotein II inhibitor; VDss - Steady-state volume of distribution; FU-h - Fraction unbound (human); BBB-P - Blood-brain barrier permeability; CNS-P - Central nervous system permeability; CYP - Cytochrome P; S - Substrate; I Inhibitor; OCT2 - Organic cation transport2; MTD - Maximum tolerated dose (human); ORAT - Oral Rat Acute Toxicity (LD50); ORCT - Oral Rat Chronic Toxicity (LOAEL); HT - Hepatotoxicity; SS -Skin Sensitisation; TPT - T.Pyriformis toxicity; MT - Minnow toxicity.

The binding energy and binding interactions are available in Table 4. Out of five designed compounds, compounds 1 and 2 show better binding energies of -8.12 and -9.16 $\mathrm{kcal} / \mathrm{mol}$, respectively. Compound 1 has two hydrogen-bonding interactions, and compound 2 has four hydrogen-bonding interactions. These hydrogen bonding interactions are exclusively involved in the biological response by chemical structure activity as an MPO inhibitor [45, 46]. Based on the in-silico validation, we conclude the following; i) compounds 1 and 2 hold hydrogen bonding interactions with high binding energy, so it may have higher bioactivity for in vitro system, ii) compounds bonded (non-covalent) with active site amino acid residues exhibiting inhibition efficiency. This will also reveal that compounds 1 and 2 are a reversible inhibitor of MPO. Figure 2 shows the 2-dimensional bonding interactions of the highest 
binding energy for compounds 1 and 2 with amino acid residues. For compounds 3, 4, and 5, binding interactions are available in supplementary information file as Figure S15 to S17.

The molecular docking study showed that compound 1 and compound 2 have hydrogen bonding, pi-alkyl, and pi-anion type of intermolecular bonding interactions with the MPO. These intermolecular interactions help to deactivate the protein and prevent MPO-mediated oxidative pathways. Similarly, hydrogen and hydrophobic molecular interactions help modify the ligand's conformation, which exactly fits well within the active site of the MPO.

\subsection{Chemical synthesis and characterization.}

Designed compounds were synthesized using two different synthetic methods without conceding biological activity available in the parent structures. For method-1, 4-nitrobenzoic acid was coupled with various bioactive phenols in the presence of different coupling methods and solvents. In method-1, we have used 4-dimethyl aminopyridine (4-DMAP) and N-(3dimethylaminopropyl)-N-ethyl carbodiimide hydrochloride (EDCI) to synthesize the final compounds with high yield and purity. The yield optimizations by method 1 using various reagents and conditions are depicted in Table 4. In method-2, 4-nitrobenzoyl chloride was treated with bioactive phenols in the presence of triethylamine and dichloromethane. Both methods can be adopted for the pilot-scale synthesis of lead molecules. However, method 2 is more likely feasible in terms of ease of operation, less expensive starting materials, and reagents.

Further, the method offers high yield products with a reasonable level of purity. It is highly safe for the environment. The synthesized phytophenol chemical scaffolds were characterized by ${ }^{1} \mathrm{H} \&{ }^{13} \mathrm{C}$ NMR, LC-MS/MS techniques, and single-crystal XRD was analyzed for the compound-1. The synthetic procedure and spectral data are available in the supplementary information. Scheme 1 shows schematic representations of the synthesis of bioactive compounds by method-1 and method-2, respectively.

\subsection{Single-crystal XRD analysis.}

To establish final structures unequivocally, the crystallization technique was employed. In this investigation line, crystal growth methodology was utilized by diverse circumstances using solution growth, such as slow evaporation at RT and cooling circumstance and crystal seeding method. By implementing the protocol, the crystal growth for compound 1 by gradual evaporation at room temperature circumstance was adopted.

For other compounds, even after several attempts, a quality crystal useful for singlecrystal XRD could not be achieved. Compound 1 structure was confirmed by a single crystal analysis (Bruker Kappa Apex II Model, X-Shell, and Olex-2 Structure Solution Software). The single crystal CCDC deposition number is 1961392; compound 1 was established as a monoclinic geometrical crystal system with $\mathrm{P} 21 / \mathrm{c}$ space group. The analysis was performed at $296 \mathrm{~K}$. The complete data collection and structure refinement details are summarized in supplementary information in Table S1. The crystal structure of compound 1, is given in Figure 3 with functional group labeling.

\subsection{In vitro MPO inhibition.}

The synthesized compounds were utilized to determine MPO inhibition at various concentrations using a 96 well microplate reader at fixed wavelength-650 nm, as reported in 
the literature [38]. An assay was performed using salicyl hydroxamic acid as a positive control. The synthesized compounds have potential MPO inhibition activity in low micromolar concentration. The IC50 value of the analyzed compounds was calculated using a dose-response curve, and the values are given in Table 5. Based on this efficacy ranking, two top-ranked compounds $1\left(\mathrm{IC}_{50}=12.88 \mu \mathrm{M}\right)$ and $2\left(\mathrm{IC}_{50}=14.97 \mu \mathrm{M}\right)$, were chosen for further studies. A greater opportunity is available to develop more potent analogs to achieve MPO inhibition at either low micromolar concentration or high nanomolar concentration based on SAR studies. Further refinement is directed toward developing more active analogs utilizing nature-based phytophenols as basic building blocks to develop potential MPO inhibitors useful for CVD drug exploration [25].

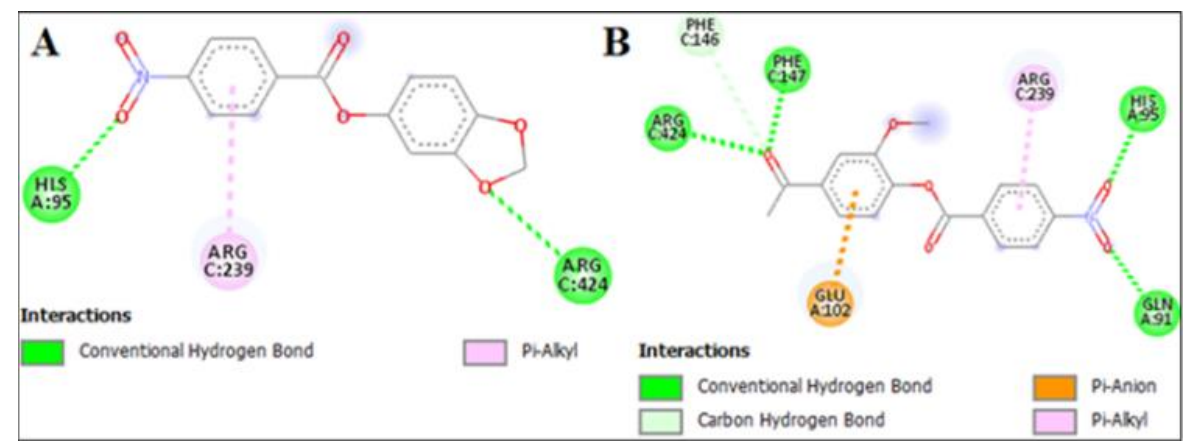

Figure 2. Molecular docking binding interaction image for first two top-ranked compounds 1 and 2.
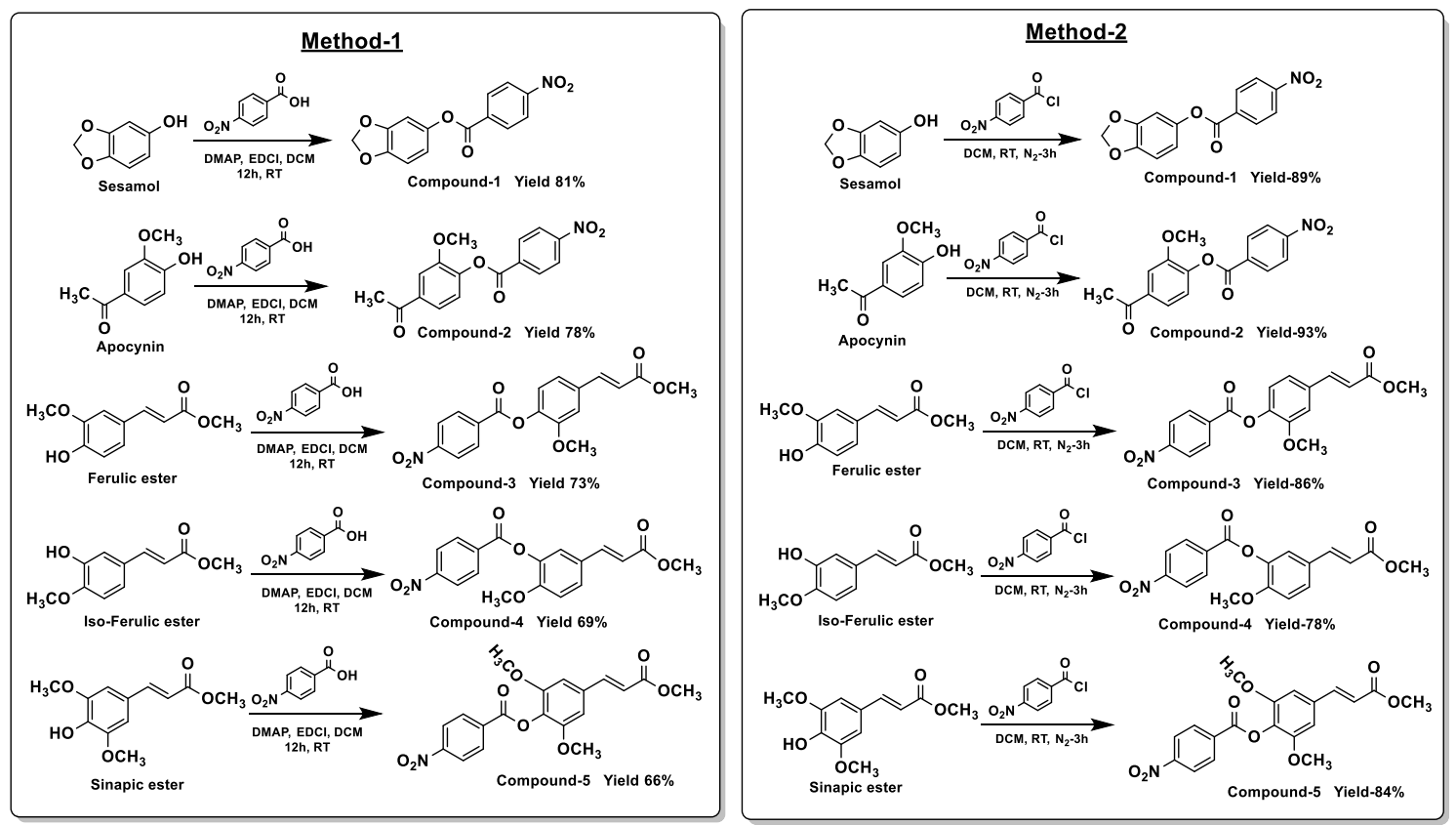

Scheme 1. Synthesis of conjugates of phytophenol based scaffolds by Method 1 and Method 2.

Table 4. Yield optimization with different reaction conditions for compounds 1 to 5 by method-1.

\begin{tabular}{|c|c|c|c|c|c|c|c|c|c|}
\hline \multirow[t]{2}{*}{ S.No } & \multirow[t]{2}{*}{ Base } & \multirow[t]{2}{*}{ Reagent } & \multirow[t]{2}{*}{ Solvent } & \multirow[t]{2}{*}{ Reaction Condition } & \multicolumn{5}{|c|}{$\%$ of Yield (Isolated) } \\
\hline & & & & & C-1 & C-2 & C-3 & C-4 & C-5 \\
\hline 1 & PPY & $\mathrm{DCC}$ & DMF & RT, 12h & 61 & 72 & 65 & 58 & 60 \\
\hline 2 & DMAP & $\mathrm{DCC}$ & DCM & RT, 12h & 73 & 70 & 59 & 65 & 59 \\
\hline 3 & DMAP & EDCI & DCM & $\mathrm{RT}, 12 \mathrm{~h}$ & 81 & 78 & 73 & 69 & 66 \\
\hline 4 & PPY & EDCI & DCM & $\mathrm{RT}, 12 \mathrm{~h}$ & 68 & 64 & 68 & 63 & 55 \\
\hline 5 & DMAP & EDCI & Benzene & $\mathrm{RT}, 12 \mathrm{~h}$ & 59 & 53 & 63 & 59 & 53 \\
\hline
\end{tabular}




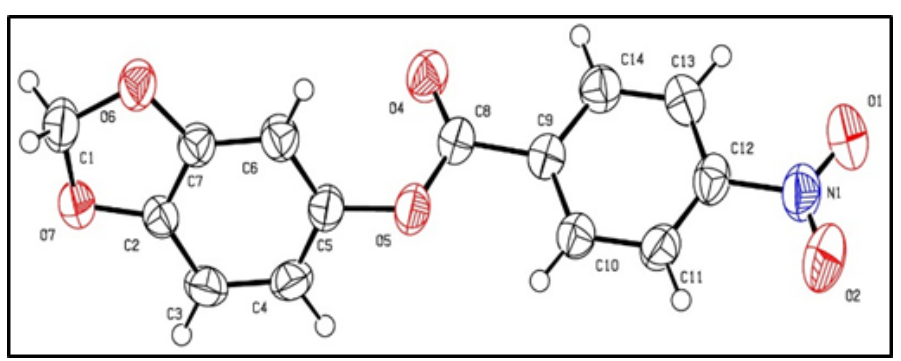

Figure 3. Single crystal structure of compound 1 with atom labeling.

Table 5. In silico binging energy, binding interactions, and in vitro MPO inhibition ( $\left.\mathrm{IC}_{50}\right)$ values of the synthesized conjugates 1 to 5 .

\begin{tabular}{l|l|l|l} 
Code & $\begin{array}{l}\text { Binding Energy } \\
\boldsymbol{A G} \text { Score }(\text { Kcal/mol })\end{array}$ & Ligand-Receptor Interactions & $\begin{array}{l}\text { In } \\
\text { vitro }\end{array} \begin{array}{c}\text { MPO } \\
\text { IC }\end{array}$ \\
\hline $\mathbf{1}$ & -8.12 & Halues $(\boldsymbol{\mu M})$ \\
\hline $\mathbf{2}$ & -9.16 & GLN:91, ARG:239, ARG:424 & 12.88 \\
\hline $\mathbf{3}$ & -7.04 & GLU:116, PRO:145, PHE:147, THR:238, ARG:239, ARG:424 & 21.04 \\
\hline $\mathbf{4}$ & -6.67 & PRO:145, PHE:147, ARG:239, PHE:366 & 46.87 \\
\hline $\mathbf{5}$ & -6.82 & $\begin{array}{l}\text { PHO:145, PHE:146, PHE:147, ARG:239, PHE:366, PHE:407, } \\
\text { LEU:415, ARG:424 }\end{array}$ & 29.56
\end{tabular}

\subsection{Structure-activity relationship.}

Based on the in silico and in vitro analysis, two lead molecules (compounds 1 and 2) were identified for further bio-analysis. In that, methylenedioxy bridge (sesamol) and acetophenone (apocynin) are established bioactive pharmacophores. In all the synthesized molecules (compounds 1 to 5), the common motif, nitrobenzoate, is chemically linked with an ester linkage. The literature report suggests [47] that the polar group (nitro) improves the binding interaction for the in vivo target, which was clearly observed in our docking studies. Figure 2 shows the lead molecular binding interaction of the docked protein-ligand complex. The nitro group shares hydrogen bonding interaction with targeted protein. Hydrogen bonding is capable of exerting a specific role for improving binding energy and better fit. The nitrobenzoate is available in all the compounds, but sesamol (1) and apocynin (2) substituents exhibited the best fit with the highest binding energy $(-8.12$ and $-9.16 \mathrm{kcal} / \mathrm{mol}$, respectively). For compounds 1 and 2, the in vitro results reveal better bio-activity up to a two to four-fold increase in activity compared with synthesized compounds 3, 4, and 5. Overall, in the presence of a nitro group, bioactivity seems to improve. At the same time, sesamol and apocynin also increase the activity compared with other phytophenol structures. These observations give a wider opportunity for further development to identify better acting molecular entities.

\subsection{Purity of the lead conjugates 1 and 2.}

For the biological study, we have used compounds with more than $90 \%$ purity. By UPLC-DAD analysis, the purity of compounds 1 and 2 were $99.97 \%$ and $98.98 \%$, respectively. Figure S18 and S19 (Supplementary Information) represent the UPLC-DAD chromatogram of compound 1 and 2.

\subsection{Ex vivo anti-inflammatory assay.}

Next, the anti-inflammatory activities of the conjugates 1 and 2 were assayed as per the previous literature report. The $\mathrm{RBC}$ was taken in a hypotonic solution, resulting in the variation in solute concentration leading to the RBC cell wall's rupturing. This will lead to the overproduction of radicals triggering the peroxidation cycle. The percentage of RBC 
stabilization by different concentrations of lead compounds 1 and 2 were shown in Figure 4 . In the presence of synthetic phytophenolic conjugates 1 and 2, the level of inflammation was reduced due to interference from synthesized conjugates. The hemolytic activity of synthesized conjugates 1 and 2 was found to increase at higher concentrations. In $20 \mu \mathrm{M}$ of compound $1 \&$ 2 shows $\sim 17 \%$ anti-inflammatory activity. When concentration increases up to $100 \mu \mathrm{M}$, the activity also increases up to $\sim 85 \%$ for compound 1 and $\sim 75 \%$ for compound 2 . The activity was compared with positive control Aceclofenac (an anti-inflammatory drug). It showed $\sim 73 \%$ of anti-inflammatory activity at $100 \mu \mathrm{M}$.
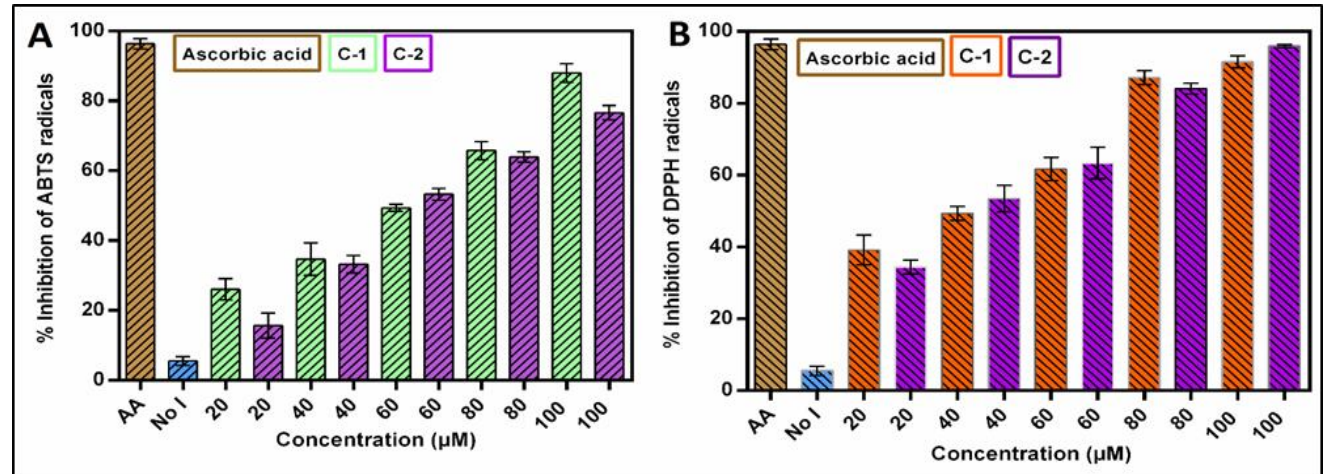

Figure 4. Measurement of ant-inflammatory activity of two synthesized conjugates in the presence of human RBC and graph A \& B represent activity measurement for $1 \& 2$ respectively with positive control.

\subsection{In vitro antioxidant assay.}

Measurement of the antioxidant activity of synthesized conjugates is critical because of the implication of free radicals in the MPO-mediated oxidative reaction of biomolecules. For example, biomarkers for MPO-mediated reactions are dityrosine, and nitrotyrosine. They are generated from tyrosine radical from MPO-catalyzed reaction. Hence, measurement of the conjugates' antioxidant activity for this investigation is necessary to corroborate the results. The antioxidant activity is determined by observing the change in DPPH radical absorption, which absorbs at $517 \mathrm{~nm}$. Results were reported as percentage inhibition of free radical generated during the reaction in the presence of lead compounds 1 and 2 with increasing concentrations.

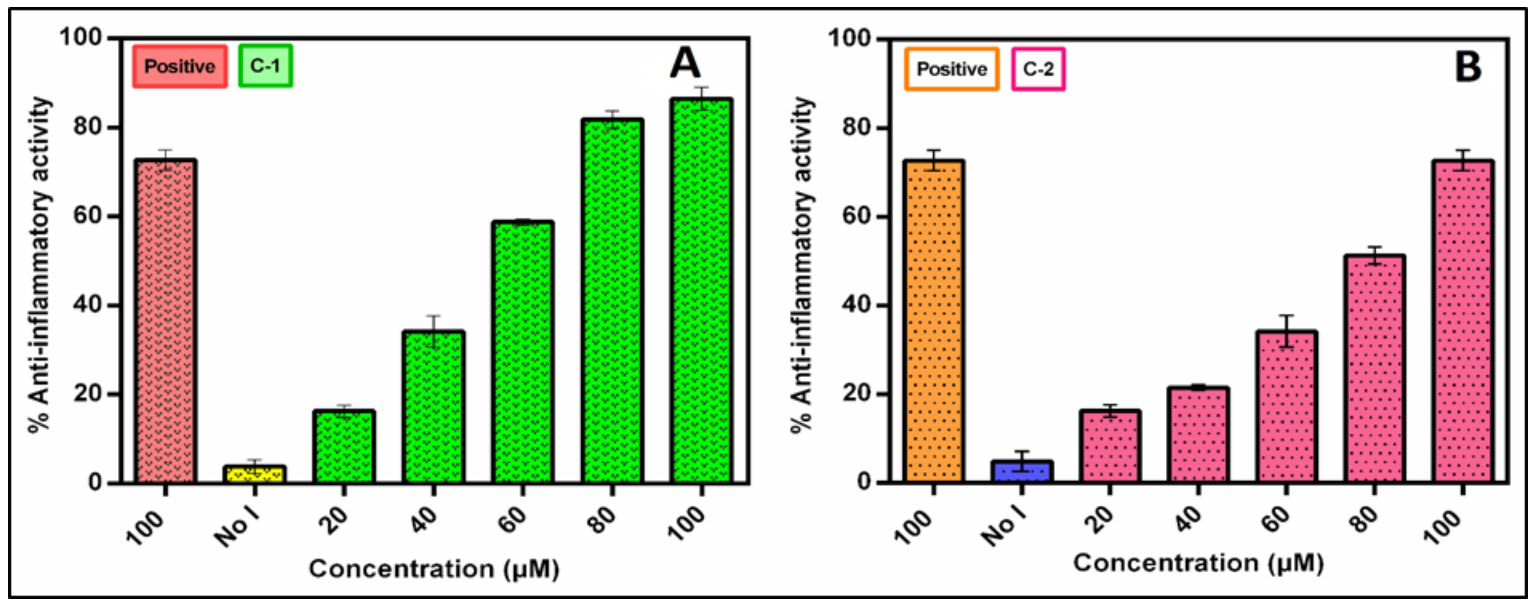

Figure 5. Free radicals scavenging activity for lead compounds 1 and 2. A represents the ABTS method, B represents DPPH method of radical scavenging assay.

Results were reported as percentage inhibition of free radical generated during the reaction in the presence of lead compounds 1 and 2 with increasing concentrations. Similarly, 
ABTS antioxidant assay was performed without using any substrate. ABTS's noted chemical properties include high aqueous solubility and chemical stability with an absorption maximum at $734 \mathrm{~nm}$. Figure 5 provides the details of an antioxidant assay using DPPH and ABTS radicals for lead compounds 1 and 2 with increasing concentrations. In vitro, antioxidant study with synthesized lead compounds and ascorbic acid as positive control showed a correlation in antioxidant activity. However, the level of activity in comparison to known antioxidants appears to be moderate.

\subsection{MTT cell viability assay.}

MTT cell viability assay was performed using RAW-264.7 macrophage cells. This study was used to analyze the toxicity of lead compounds 1 and 2. Results showed that both compounds are well safe for human consumptions. We also predicted the same outcome since the synthesized conjugates are derived using natural building blocks. The results are indicated in Table 6 as \% cell viability for the lead compound 1 and 2 at various concentrations.

Table 6. Cell viability result for RAW Macrophages cell line with different concentration of lead conjugates.

\begin{tabular}{c|c|c}
\multirow{2}{*}{$\begin{array}{c}\text { Conjugate concentration } \\
(\boldsymbol{\mu M})\end{array}$} & \multicolumn{2}{|c}{$\%$ of Cell viability } \\
\cline { 2 - 3 } $\begin{array}{c}\text { Control } \\
20\end{array}$ & 100 & Compound-2 \\
\hline 40 & 91.06 & 100 \\
\hline 60 & 86.93 & 93.21 \\
\hline 80 & 80.16 & 83.04 \\
\hline 100 & 74.08 & 78.22 \\
\hline & 69.43 & 60.92 \\
\hline
\end{tabular}

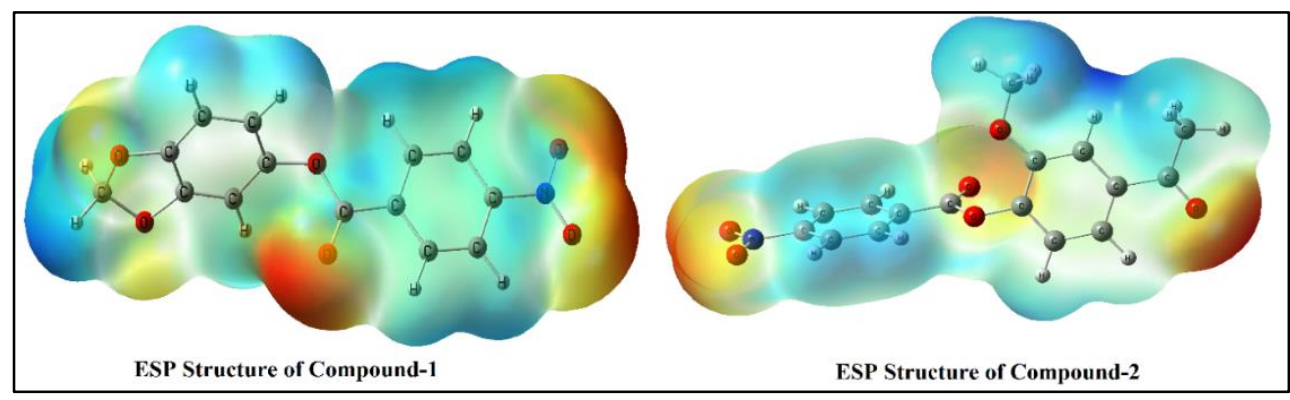

Figure 6. ESP image of the phytophenol lead compound-1 and compound-2.

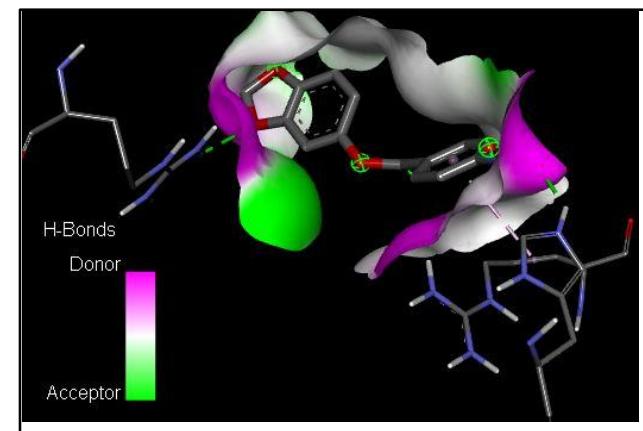

Compound-1 bonding interactions with MPO

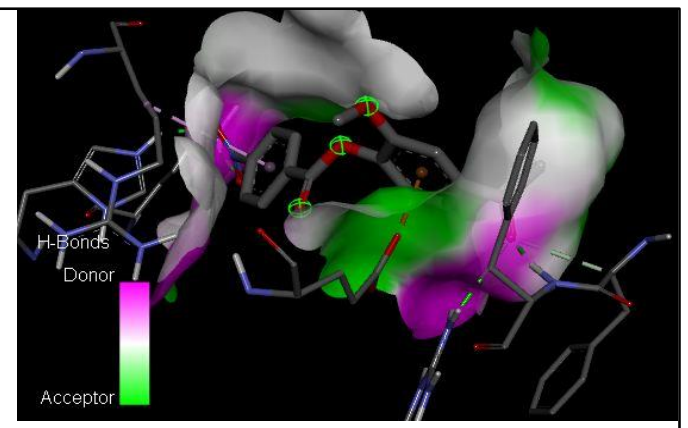

Compound-2 bonding interactions with MPO

Figure 7. H-Bonding donor \& acceptor surface image for lead molecules $\mathbf{1}$ and $\mathbf{2}$ interacted with biomolecule receptor (MPO protein).

\subsection{Surface image for ligand and receptor interaction.}

Electrostatic Potential (ESP) of the lead ligand was utilized to identify the potential functional pharmacophore group molecular interactions (Molecular docking) with MPO 
receptor. This ESP surface mapping structure provides the ligand's pharmacophoric electron charges, either positive (+EP), negative (-EP), or neutral electrostatic potentials. Similarly, MPO receptor with ligand interactions is shown by molecular docking H-bond donor surface image. This charge was provided based on a different color, which guides the active site positions and physicochemical properties $[23,26]$. The lead molecules' ESP surface mapping was represented in Figure 6, and the H-Bond donor \& acceptor surface image was given in Figure 7.

In the ESP image, red-colored portions represent the nucleophilic nature, blue color portions represent the electrophilic nature, and white color portions represent the neutral atom. Similarly, in docking H-bonding surface image, the green color represents the H-bond acceptor, the pink color represents the H-Bond donor, and the white color shows neutral. For compound 1, methylenedioxy, nitro, and carbonyl groups are nucleophilic, and they interacted within the MPO receptor site as follows; nitro and methylenedioxy group contained oxygen (nucleophilic atoms) interacted with MPO active site residues such as Histidine-95 and Arginine-424 (Hbond donor portions) to form two hydrogen bonding. Similarly, nitro substituted phenyl ring (slightly electrophilic nature) interacted with Arginine-239 (neutral residues) to create a $\pi$-alkyl bonding.

For compound 2, nitro, ester linkage, methoxy, and carbonyl in acetyl groups are nucleophilic. These groups interacted with the MPO receptor site. In compound 2, oxygen in the nitro group (high nucleophilic portion) interacted with $\mathrm{H}$-bond donor residues such as Histidine-95, and Glutamine-91, to form hydrogen bonding. Nitro group substituted phenyl ring (moderate electrophilic nature) interacted with Arginine-239 as a $\pi$-alkyl bond, followed by the acetyl group substituted phenyl ring (neutral portion) interacted Glutamin-102 (H-bond acceptor group) to form a $\pi$-anion type of interactions. Oxygen in acetyl group (Nucleophilic) interacted with Phenylalanine-146 \& 147, and Arginin-424 (H-bond donor groups) as hydrogen bonding interactions. This bonding interaction surface image was provided below. Based on this analysis, we firmly believe that our lead molecules 1 and 2 have possible interactions with MPO active site receptors.

\section{Conclusions}

This study's collective results divulge that phytophenol conjugates can be considered an effective inhibitor of MPO. The structure confirmation by NMR, Mass, and XRD results helped validate the reported entity's chemical structure, geometry, space group, and molecular interactions. The lead conjugates 1 and 2 have inhibited the target protein, MPO. It predictably happened due to intermolecular hydrogen bonding interaction with active site amino acid residues within active site pocket, forming a tight binding. Further, the drug likenesses of physicochemical data showed that compounds have zero violations. The protein inhibition studies revealed that out of five molecules, compounds 1 and 2 inhibited the human leucocyte MPO protein with minimum concentration. Selected lead molecules showed excellent antiinflammatory properties by measuring RBC erythrocyte blood cells. The lead conjugates were analyzed for free radical scavenging ability using ABTS and DPPH protocol. Both compounds possess excellent free radical scavenging ability. The lead compounds are non-toxic and highly safe at higher concentration against RAW macrophage cell line by MTT protocol. Also, the quantum chemical parameter was evaluated using DFT - B3LYP/6-311G** method. The lead compounds' ESP with their interactive sites was compared with H-bond donor and acceptor surface mapping for ligand and receptor interactions by molecular docking study. Collectively 
the outcome of this investigation demonstrated that compounds 1 and 2 could be considered as potential CVD therapeutic agents against inflammation-mediated by MPO oxidation.

\section{Funding}

This research received no external funding.

\section{Acknowledgments}

DR is grateful to VIT-RGEMS for financial support. We like to thank Dr.A.Senthil Kumar, Department of Chemistry, School of Advanced Science, VIT Vellore, for helping collaborative studies. We also thank DST-VIT-FIST for NMR, VIT-SIF for GC-MS, FT-IR, and other instrumentation facilities.

\section{Conflicts of Interest}

The authors declare no conflict of interest.

\section{References}

1. Taylor, A.P.; Robinson, R.P.; Fobian, Y.M.; Blakemore, D.C.; Jones, L.H.; Fadeyi, O. Modern advances in heterocyclic chemistry in drug discovery. Org. Biomol. Chem. 2016, 14, 6611-6637, http://dx.doi.org/10.1039/C6OB00936K.

2. Saini, M.S.; Kumar, A.; Dwivedi, J.; Singh, R. A review: biological significances of heterocyclic compounds. Int. J. Pharm. Sci. Res. 2013, 4, 66-77.

3. Asif, M.; Singh, A.; Siddiqui, A.A. The effect of pyridazine compounds on the cardiovascular system. Medicinal Chemistry Research 2012, 21, 3336-3346, https://doi.org/10.1007/s00044-011-9835-6.

4. Nana, F.; Kuete, V.; Zaharia, V.; Ngameni, B.; Sandjo, L.P. Synthesis of Functionalized 1-Aryl-3phenylthiazolylpropanoids and Their Potential as Anticancer Agents. ChemistrySelect 2020, 5, 7675-7678, https://doi.org/10.1002/slct.202002060.

5. Murray, M. Toxicological Actions of Plant-Derived and Anthropogenic Methylenedioxyphenyl-Substituted Chemicals in Mammals and Insects. Journal of Toxicology and Environmental Health, Part B 2012, 15, 365395, https://doi.org/10.1080/10937404.2012.705105.

6. Hariram, M.; Vivekanandhan, S. Phytochemical Process for the Functionalization of Materials with Metal Nanoparticles: Current Trends and Future Perspectives. ChemistrySelect 2018, 3, 13561-13585, https://doi.org/10.1002/slct.201802748.

7. Liu, C.; Desikan, R.; Ying, Z.; Gushchina, L.; Kampfrath, T.; Deiuliis, J.; Wang, A.; Xu, X.; Zhong, J.; Rao, X.; Sun, Q.; Maiseyeu, A.; Parthasarathy, S.; Rajagopalan, S. Effects of a Novel Pharmacologic Inhibitor of Myeloperoxidase in a Mouse Atherosclerosis Model. PLOS ONE 2012, 7 , https://doi.org/10.1371/journal.pone.0050767.

8. Daugherty, A.; Dunn, J.L.; Rateri, D.L.; Heinecke, J.W. Myeloperoxidase, a catalyst for lipoprotein oxidation, is expressed in human atherosclerotic lesions. The Journal of Clinical Investigation 1994, 94, 437444, https://doi.org/10.1172/JCI117342.

9. Carr Anitra, C.; McCall Mark, R.; Frei, B. Oxidation of LDL by Myeloperoxidase and Reactive Nitrogen Species. Arteriosclerosis, Thrombosis, and Vascular Biology 2000, 20, 1716-1723, https://doi.org/10.1161/01.atv.20.7.1716.

10. Carnuta, M.G.; Stancu, C.S.; Toma, L.; Sanda, G.M.; Niculescu, L.S.; Deleanu, M.; Popescu, A.C.; Popescu, M.R.; Vlad, A.; Dimulescu, D.R.; Simionescu, M.; Sima, A.V. Dysfunctional high-density lipoproteins have distinct composition, diminished anti-inflammatory potential and discriminate acute coronary syndrome from stable coronary artery disease patients. Scientific Reports 2017, 7, https://doi.org/10.1038/s41598-01707821-5.

11. Ying, Z.; Desikan, R.; Xu, X.; Maiseyeu, A.; Liu, C.; Sun, Q.; Ziouzenkova, O.; Parthasarathy, S.; Rajagopalan, S. Modified methylenedioxyphenol analogs lower LDL cholesterol through induction of LDL receptor expression. Journal of lipid research 2012, 53, 879-887, https://doi.org/10.1194/jlr.M022806.

12. Ying, Z.; Kherada, N.; Kampfrath, T.; Mihai, G.; Simonetti, O.; Desikan, R.; Selvendiran, K.; Sun, Q.; Ziouzenkova, O.; Parthasarathy, S.; Rajagopalan, S. A Modified Sesamol Derivative Inhibits Progression of Atherosclerosis. Arteriosclerosis, Thrombosis, and Vascular Biology 2011, 31, 536-542, https://doi.org/10.1161/ATVBAHA.110.219287. 
13. Shao, B.; Oda, M.N.; Oram, J.F.; Heinecke, J.W. Myeloperoxidase: An Oxidative Pathway for Generating Dysfunctional High-Density Lipoprotein. Chemical Research in Toxicology 2010, 23, 447-454, https://doi.org/10.1021/tx9003775.

14. Davis, J.M.; Zhao, Z.; Stock, H.S.; Mehl, K.A.; Buggy, J.; Hand, G.A. Central nervous system effects of caffeine and adenosine on fatigue. American Journal of Physiology-Regulatory, Integrative and Comparative Physiology 2003, 284, R399-R404, https://doi.org/10.1152/ajpregu.00386.2002.

15. Sowmya Shree, G.; Yogendra Prasad, K.; Arpitha, H.S.; Deepika, U.R.; Nawneet Kumar, K.; Mondal, P.; Ganesan, P. $\beta$-carotene at physiologically attainable concentration induces apoptosis and down-regulates cell survival and antioxidant markers in human breast cancer (MCF-7) cells. Molecular and Cellular Biochemistry 2017, 436, 1-12, https://doi.org/10.1007/s11010-017-3071-4.

16. Stahl, W.; Sies, H. $\beta$-Carotene and other carotenoids in protection from sunlight. The American Journal of Clinical Nutrition 2012, 96, 1179S-1184S, https://doi.org/10.3945/ajcn.112.034819.

17. Hoda, M.E.; Pierre, S.H. The Antidiabetic Potential of Quercetin: Underlying Mechanisms. Current Medicinal Chemistry 2017, 24, 355-364, https://doi.org/10.2174/0929867323666160909153707.

18. Li, Y.; Yao, J.; Han, C.; Yang, J.; Chaudhry, M.T.; Wang, S.; Liu, H.; Yin, Y. Quercetin, Inflammation and Immunity. Nutrients 2016, 8, https://doi.org/10.3390/nu8030167.

19. Narasimhulu, C.A.; Selvarajan, K.; Burge, K.; Litvinov, D.; Sengupta, B.; Parthasarathy, S. Oxidized LDLbinding Cationic Peptides and Proteins in Inflammation and Atherosclerosis: Novel Insights. Arterioscler. Thromb. Vasc. Biol. 2015, 35, A347-A347.

20. Narasimhulu, C.A.; Selvarajan, K.; Litvinov, D.; Parthasarathy, S. Anti-Atherosclerotic and AntiInflammatory Actions of Sesame Oil. Journal of Medicinal Food 2015, 18, 11-20, https://doi.org/10.1089/jmf.2014.0138.

21. Jayaraj, P.; Narasimhulu, C.A.; Rajagopalan, S.; Parthasarathy, S.; Desikan, R. Sesamol: a powerful functional food ingredient from sesame oil for cardioprotection. Food \& Function 2020, 11, 1198-1210, https://doi.org/10.1039/c9fo01873e.

22. Chen, H.; Li, S.; Yao, Y.; Zhou, L.; Zhao, J.; Gu, Y.; Wang, K.; Li, X. Design, synthesis, and anti-tumor activities of novel triphenylethylene-coumarin hybrids, and their interactions with Ct-DNA. Bioorg Med Chem Lett 2013, 23, 4785-4789, https://doi.org/10.1016/j.bmcl.2013.07.009.

23. Ansary, I.; Roy, H.; Das, A.; Mitra, D.; Bandyopadhyay, A.K. Regioselective Synthesis, Molecular Descriptors of (1,5-Disubstituted 1,2,3-Triazolyl)Coumarin/Quinolone Derivatives and Their Docking Studies against Cancer Targets. ChemistrySelect 2019, 4, 3486-3494, https://doi.org/10.1002/slct.201900114.

24. Bumrungpert, A.; Lilitchan, S.; Tuntipopipat, S.; Tirawanchai, N.; Komindr, S. Ferulic Acid Supplementation Improves Lipid Profiles, Oxidative Stress, and Inflammatory Status in Hyperlipidemic Subjects: A Randomized, Double-Blind, Placebo-Controlled Clinical Trial. Nutrients 2018, 10, https://doi.org/10.3390/nu10060713.

25. Jayaraj, P.; Narasimhulu, C.A.; Maiseyeu, A.; Durairaj, R.; Rao, S.; Rajagopalan, S.; Parthasarathy, S.; Desikan, R. Methoxyphenol derivatives as reversible inhibitors of myeloperoxidase as potential antiatherosclerotic agents. Future Medicinal Chemistry 2019, 12, 95-110, https://doi.org/10.4155/fmc-20190080 .

26. Simonyi, A.; Serfozo, P.; Lehmidi, T.M.; Cui, J.; Gu, Z.; Lubahn, D.B.; Sun, A.Y.; Sun, G.Y. The neuroprotective effects of apocynin. Frontiers in bioscience (Elite edition) 2012, 4, 2183-2193, https://doi.org/10.2741/535.

27. Connell, B.J.; Saleh, M.C.; Khan, B.V.; Rajagopal, D.; Saleh, T.M. UPEI-100, a conjugate of lipoic acid and apocynin, mediates neuroprotection in a rat model of ischemia/reperfusion. American Journal of PhysiologyRegulatory, Integrative and Comparative Physiology 2012, 302, R886-R895, https://doi.org/10.1152/ajpregu.00644.2011.

28. Saleh, M.C.; Connell, B.J.; Rajagopal, D.; Khan, B.V.; Abd-El-Aziz, A.S.; Kucukkaya, I.; Saleh, T.M. CoAdministration of Resveratrol and Lipoic Acid, or Their Synthetic Combination, Enhances Neuroprotection in a Rat Model of Ischemia/Reperfusion. Plos One 2014, 9, https://doi.org/10.1371/journal.pone.0087865.

29. Ying, Z.; Kherada, N.; Farrar, B.; Kampfrath, T.; Chung, Y.; Simonetti, O.; Deiuliis, J.; Desikan, R.; Khan, B.; Villamena, F.; Sun, Q.; Parthasarathy, S.; Rajagopalan, S. Lipoic acid effects on established atherosclerosis. Life Sciences 2010, 86, 95-102, https://doi.org/10.1016/j.lfs.2009.11.009.

30. Connell, B.J.; Khan, B.V.; Rajagopal, D.; Saleh, T.M. Novel Neurovascular Protective Agents: Effects of INV-155, INV-157, INV-159, and INV-161 versus Lipoic Acid and Captopril in a Rat Stroke Model. Cardiology Research and Practice 2012, 2012, https://doi.org/10.1155/2012/319230.

31. Hidayat, R.; Meiliani, M.; Yuliandra, Y.; Armenia, A. Blood pressure lowering effect of scopoletin on oxidative stress-associated hypertensive rats. Journal of Research in Pharmacy 2019, 23, 249-258, https://doi.org/10.12991/jrp.2019.131.

32. Connell, B.J.; Saleh, M.C.; Rajagopal, D.; Saleh, T.M. UPEI-400, a conjugate of lipoic acid and scopoletin, mediates neuroprotection in a rat model of ischemia/reperfusion. Food and Chemical Toxicology 2017, 100, 175-182, https://doi.org/10.1016/j.fct.2016.12.026. 
33. Shen, J.; Cheng, F.; Xu, Y.; Li, W.; Tang, Y. Estimation of ADME Properties with Substructure Pattern Recognition. Journal of Chemical Information and Modeling 2010, 50, 1034-1041, https://doi.org/10.1021/ci100104j.

34. Egbujor, M.C.; Okoro, U.C.; Okafor, S. Design, synthesis, molecular docking, antimicrobial, and antioxidant activities of new phenylsulfamoyl carboxylic acids of pharmacological interest. Medicinal Chemistry Research 2019, 28, 2118-2127, https://doi.org/10.1007/s00044-019-02440-3.

35. Pires, D.E.V.; Blundell, T.L.; Ascher, D.B. pkCSM: Predicting Small-Molecule Pharmacokinetic and Toxicity Properties Using Graph-Based Signatures. Journal of Medicinal Chemistry 2015, 58, 4066-4072, https://doi.org/10.1021/acs.jmedchem.5b00104.

36. Helgren, T.R.; Hagen, T.J. Demonstration of AutoDock as an Educational Tool for Drug Discovery. Journal of Chemical Education 2017, 94, 345-349, https://doi.org/10.1021/acs.jchemed.6b00555.

37. Rambabu, M.; Jayanthi, S. Screening approaches against claudin-4 focusing on therapeutics through molecular docking and the analysis of their relative dynamics: a theoretical approach. Journal of Receptors and Signal Transduction 2020, 40, 436-441, https://doi.org/10.1080/10799893.2020.1752717.

38. Marquez, L.A.; Dunford, H.B. Mechanism of the Oxidation of 3,5,3',5'-Tetramethylbenzidine by Myeloperoxidase Determined by Transient- and Steady-State Kinetics. Biochemistry 1997, 36, 9349-9355, https://doi.org/10.1021/bi970595j.

39. Mohana, S.; Sumathi, S. Multi-Functional Biological Effects of Palladium Nanoparticles Synthesized Using Agaricus bisporus. Journal of Cluster Science 2020, 31, 391-400, https://doi.org/10.1007/s10876-01901652-2.

40. Premkumar, J.; Sampath, P.; Sanjay, R.; Chandrakala, A.; Rajagopal, D. Synthetic Guaiacol Derivatives as Promising Myeloperoxidase Inhibitors Targeting Atherosclerotic Cardiovascular Disease. ChemMedChem 2020, 15, 1187-1199, https://doi.org/10.1002/cmdc.202000084.

41. Jayaraj, P.; Shavi, G.V.; Srinivasan, A.K.; Raghavendra, R.; Sivaramakrishna, A.; Desikan, R. A preformulation strategy for the liposome encapsulation of new thioctic acid conjugates for enhanced chemical stability and use as an efficient drug carrier for MPO-mediated atherosclerotic CVD treatment. New Journal of Chemistry 2020, 44, 2755-2767, https://doi.org/10.1039/c9nj05258e.

42. Meilhac, O.; Zhou, M.; Santanam, N.; Parthasarathy, S. Lipid peroxides induce expression of catalase in cultured vascular cells. J Lipid Res 2000, 41, 1205-1213.

43. Ogu, C.C.; Maxa, J.L. Drug Interactions Due to Cytochrome P450. Baylor University Medical Center Proceedings 2000, 13, 421-423, https://doi.org/10.1080/08998280.2000.11927719.

44. Lynch, T.; Price, A. The effect of cytochrome P450 metabolism on drug response, interactions, and adverse effects. American family physician 2007, 76, 391-396.

45. Guerra-Vargas, M.A.; Rosales-Hernández, M.C.; Martínez-Fonseca, N.; Padilla-Martínez, I.; FonsecaSabater, Y.; Martínez-Ramos, F. 2-Acetyl-4-aminoresorcinol derivatives: synthesis, antioxidant activity and molecular docking studies. Medicinal Chemistry Research 2018, 27, 1186-1197, https://doi.org/10.1007/s00044-018-2139-3.

46. Patil, R.; Das, S.; Stanley, A.; Yadav, L.; Sudhakar, A.; Varma, A.K. Optimized Hydrophobic Interactions and Hydrogen Bonding at the Target-Ligand Interface Leads the Pathways of Drug-Designing. PLOS ONE 2010, 5, https://doi.org/10.1371/journal.pone.0012029.

47. Bauzá, A.; Frontera, A.; Mooibroek, T.J. $\pi$-Hole Interactions Involving Nitro Aromatic Ligands in Protein Structures. Chemistry - $\quad$ A European Journal 2019, 25, 13436-13443, https://doi.org/10.1002/chem.201903404. 


\section{Supporting Information}

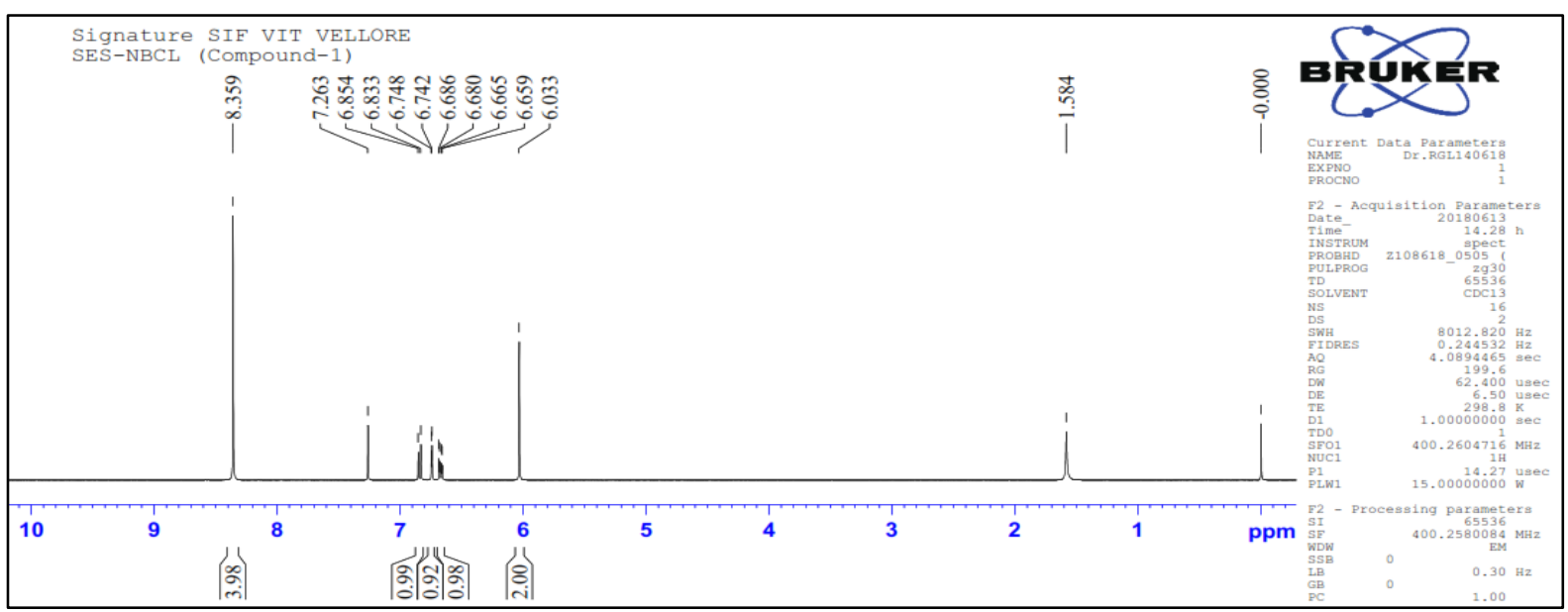

Figure S1. ${ }^{1} \mathrm{H}$ NMR Spectrum of compound 1.

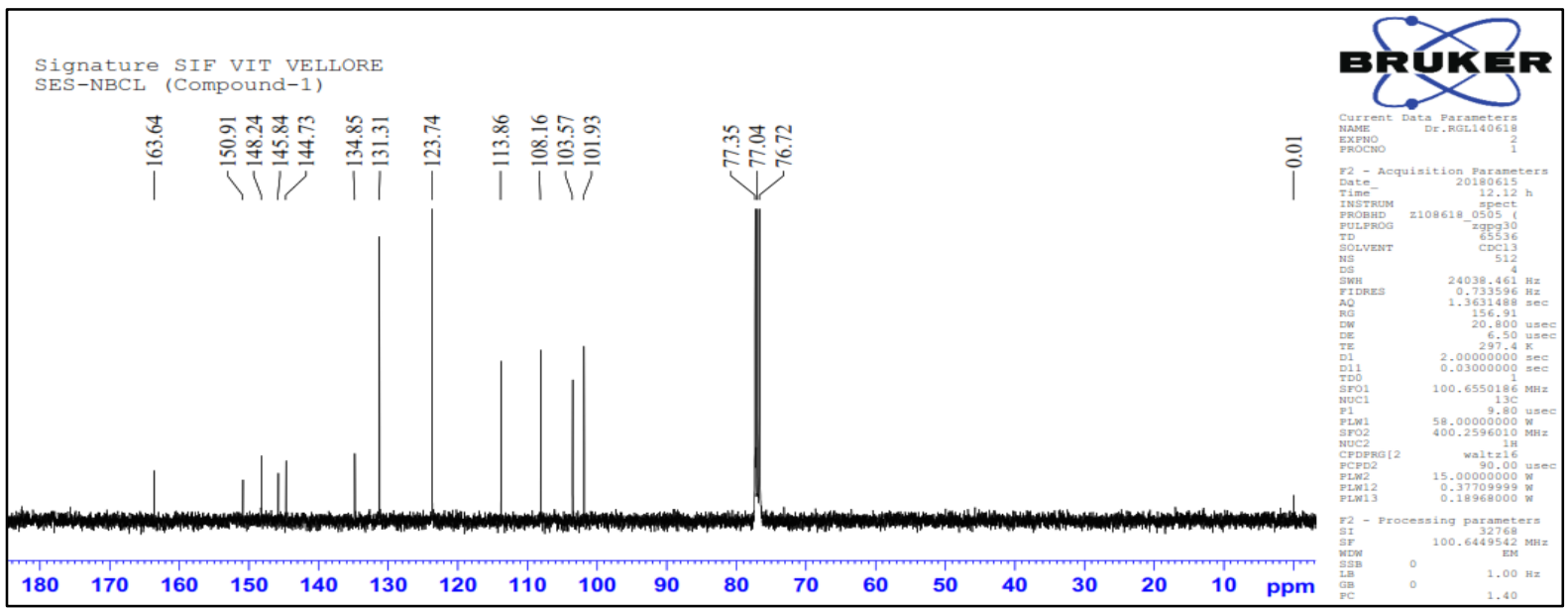

Figure S2. ${ }^{13} \mathrm{C}$ NMR spectrum of compound 1.

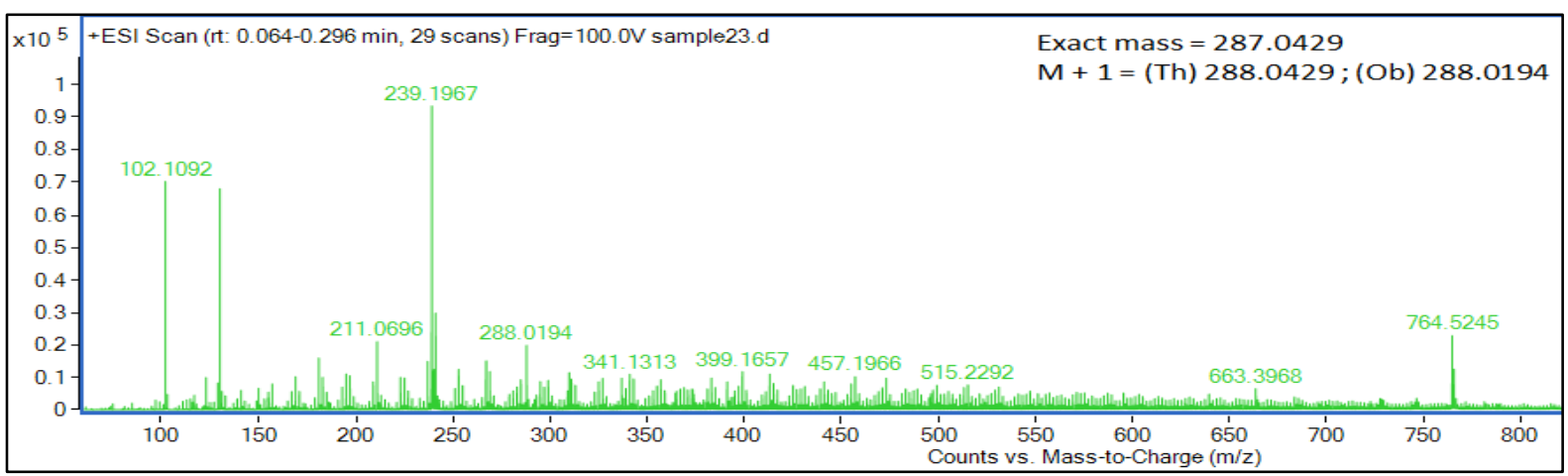

Figure S3. LC-MS/MS spectrum of compound 1. 


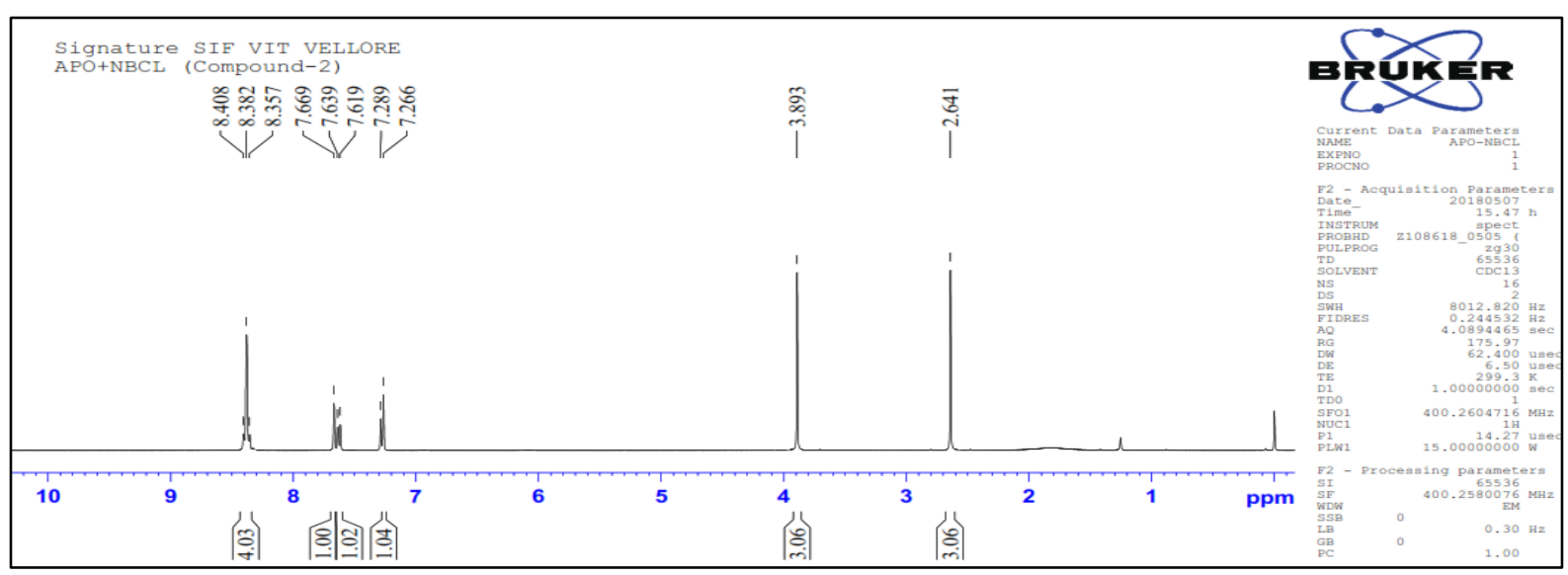

Figure S4. ${ }^{1} \mathrm{H}$ NMR spectrum for compound 2.

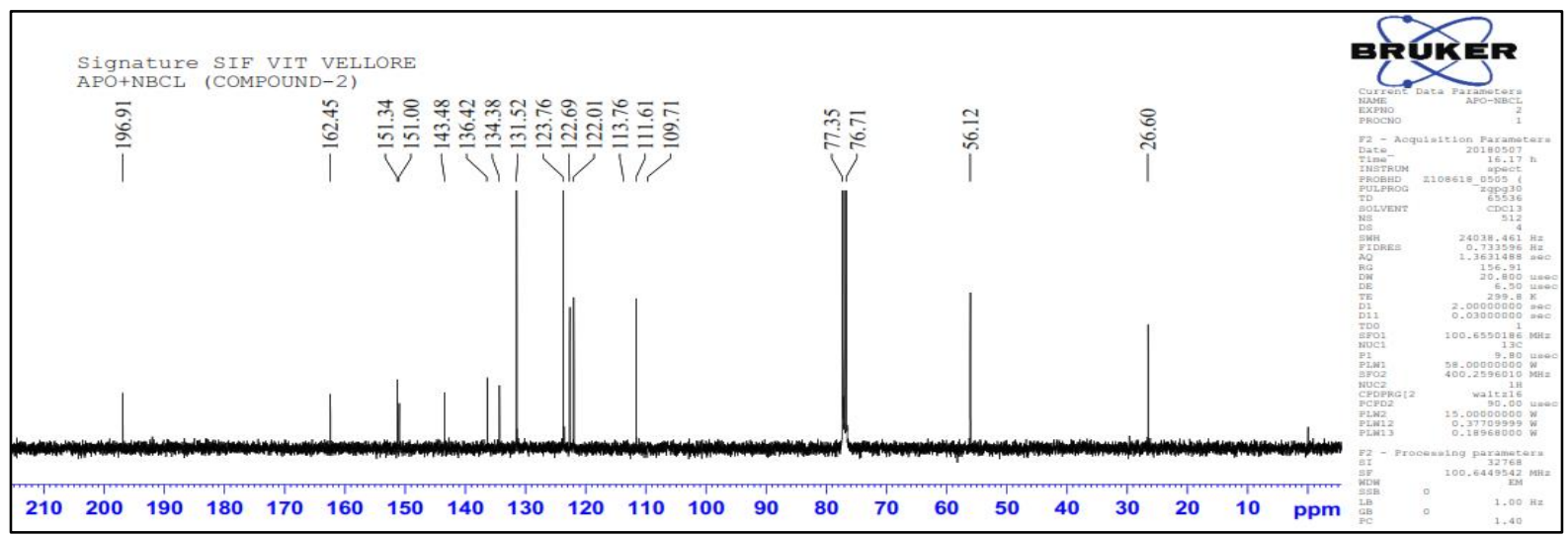

Figure S5. ${ }^{13} \mathrm{C}$ NMR spectrum for compound 2 .

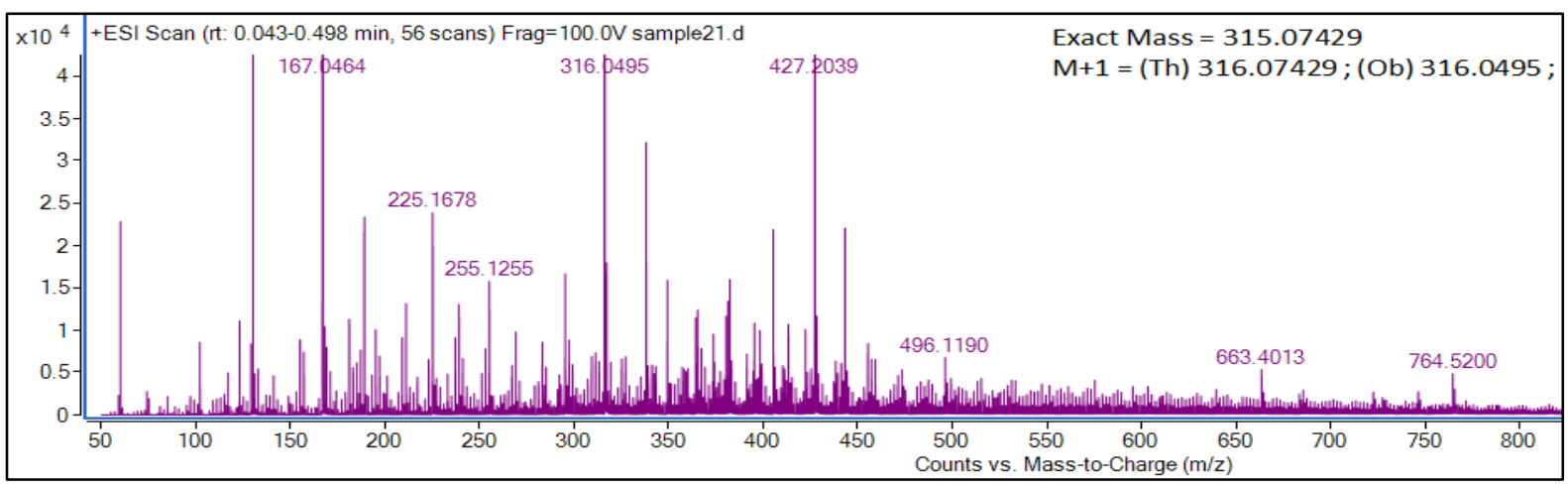

Figure S6. LC-MS/MS spectrum of compound 2.

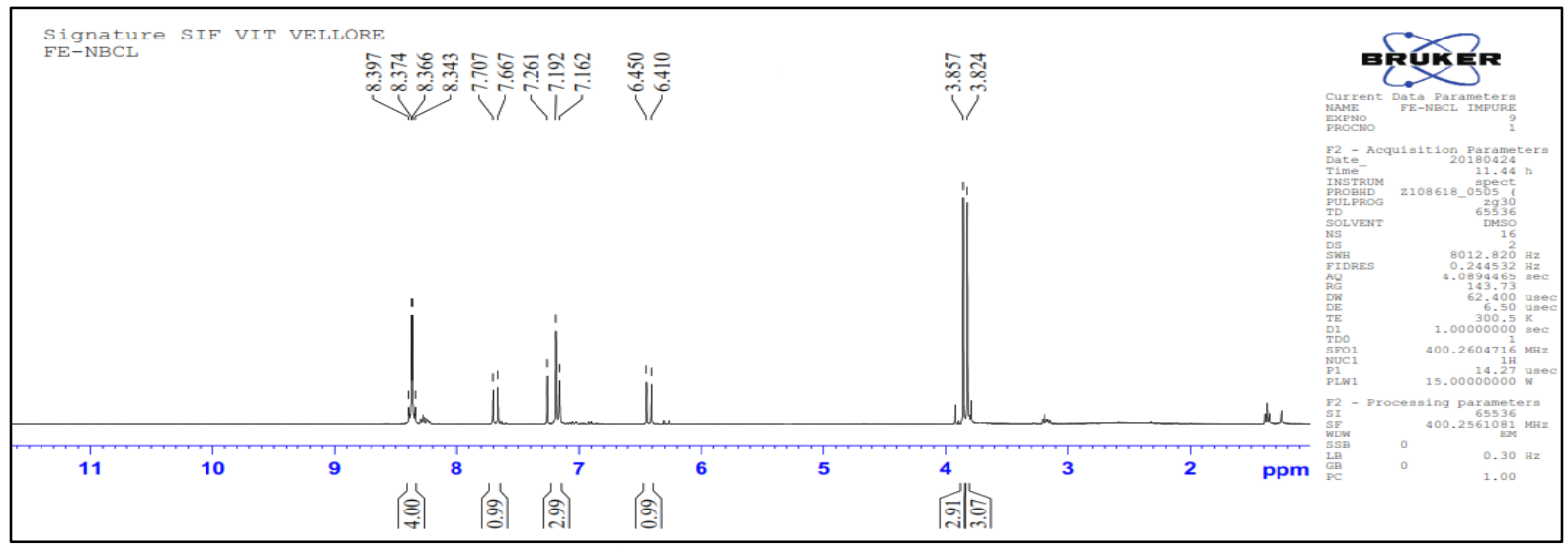

Figure S7. ${ }^{1} \mathrm{H}$ NMR spectrum for compound 3. 


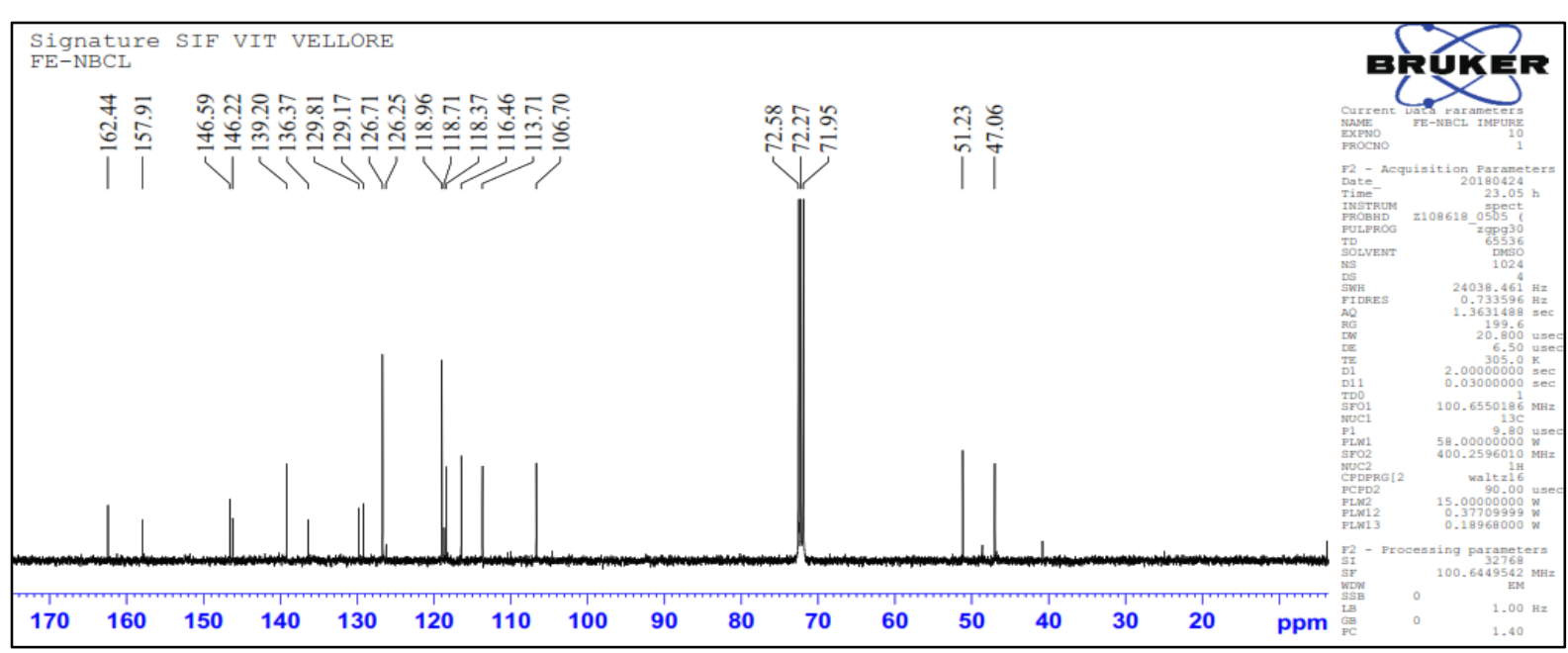

Figure S8. ${ }^{13} \mathrm{C}$ NMR spectrum for compound 3 .

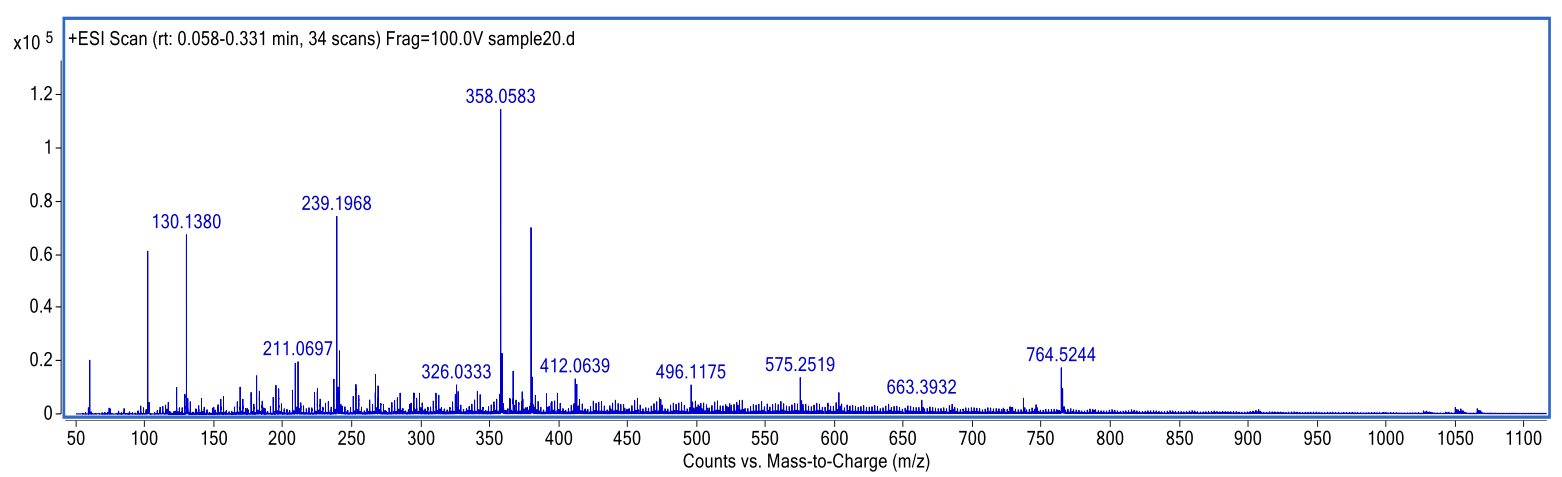

Figure S9. LC-MS/MS spectrum of compound 3.

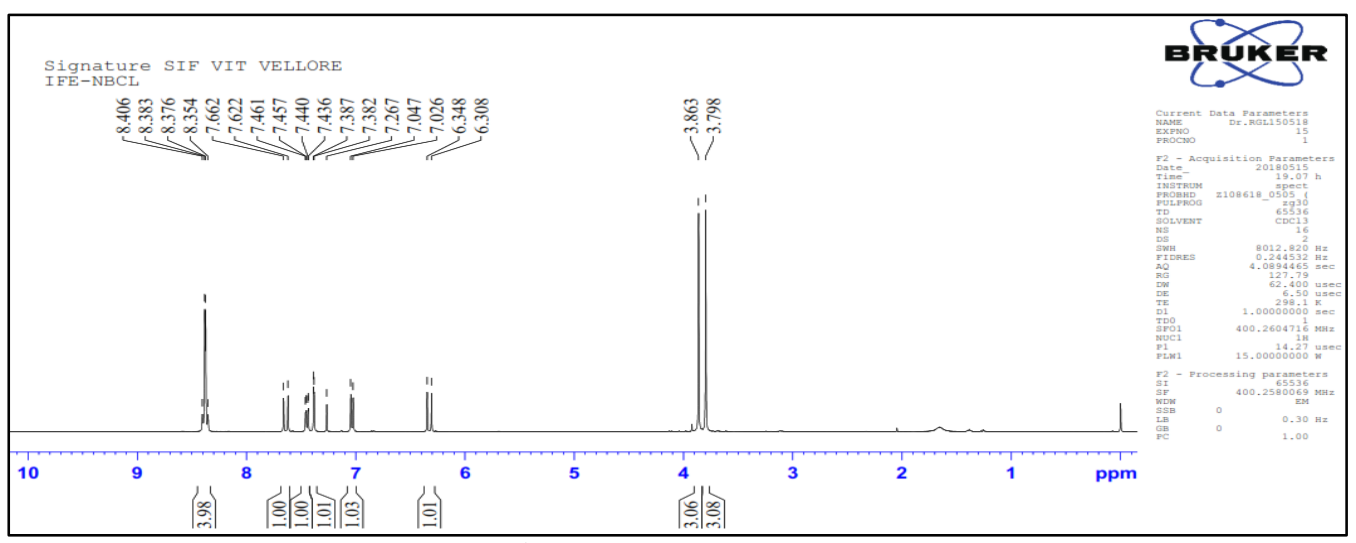

Figure S10. ${ }^{1} \mathrm{H}$ NMR spectrum for compound 4.

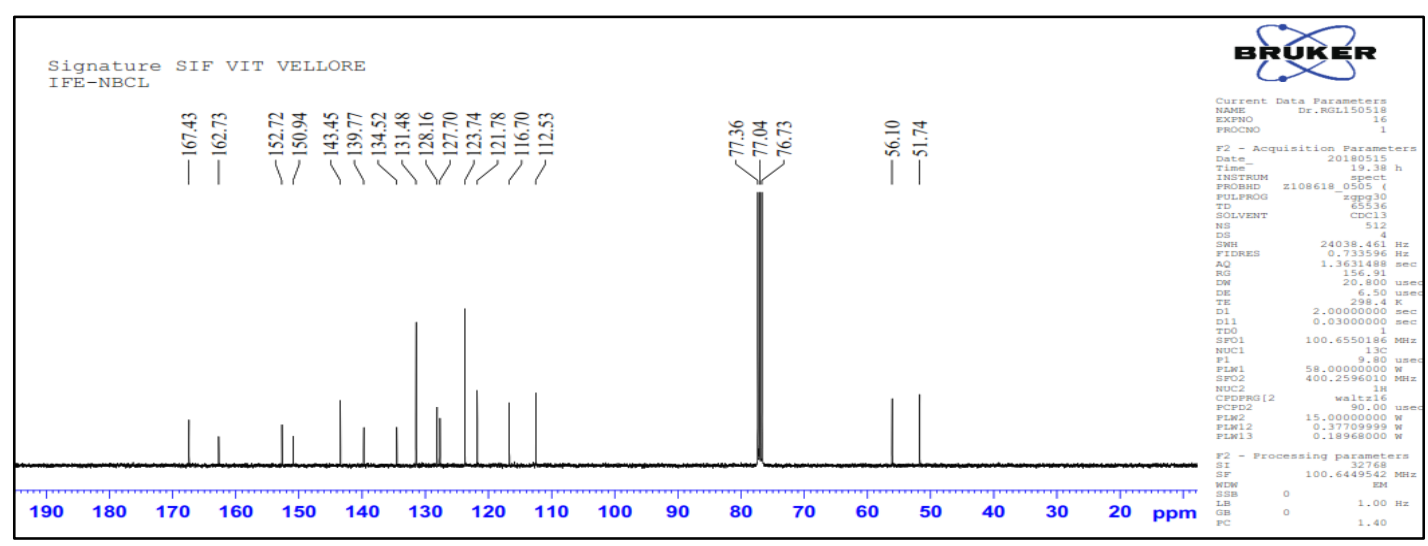

Figure S11. ${ }^{13} \mathrm{C}$ NMR spectrum for compound 4 . 


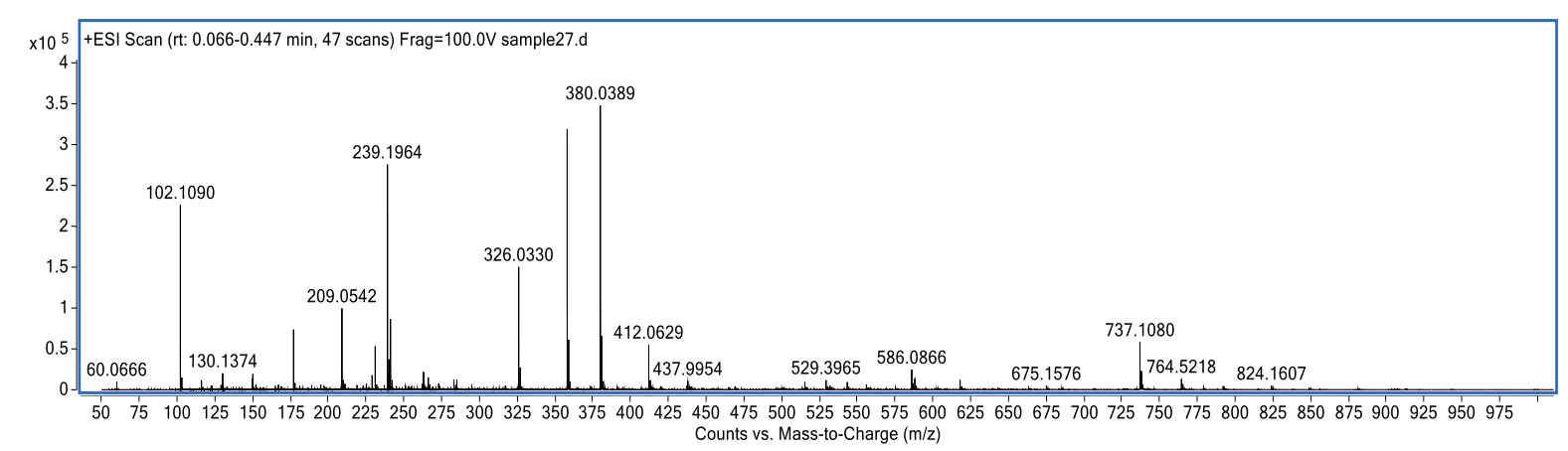

Figure S12. LC-MS/MS spectrum of compound 4.

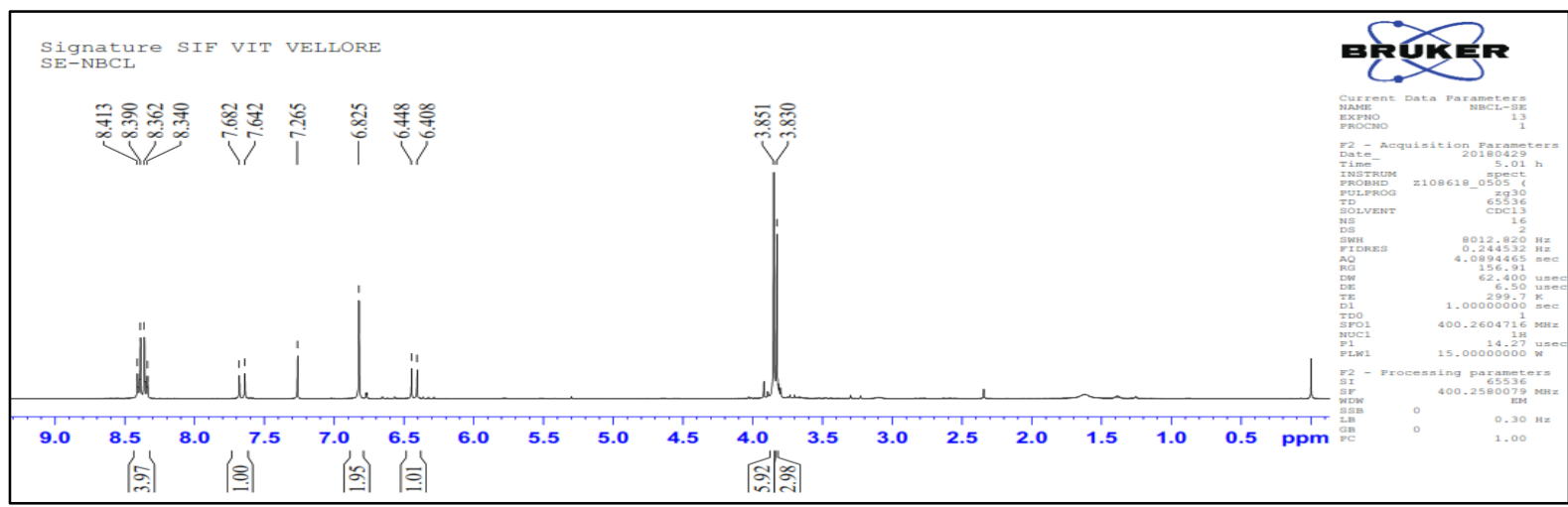

Figure S13. ${ }^{1} \mathrm{H}$ NMR spectrum for compound 5.

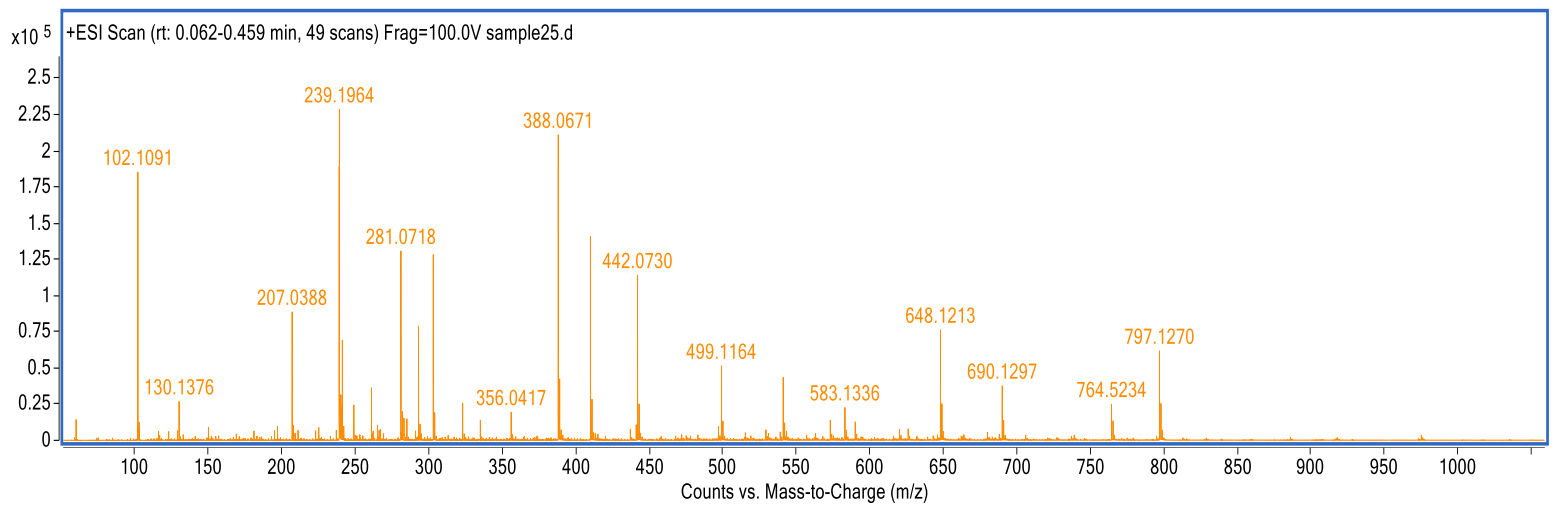

Figure S14. LC-MS/MS spectrum of compound 5.

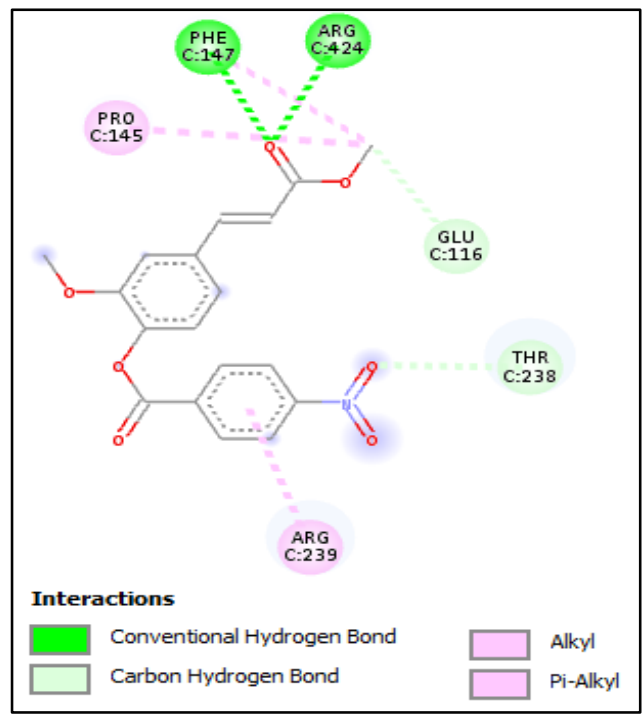

Figure S15. Bonding interactions of active site amino acid with compound-3. 


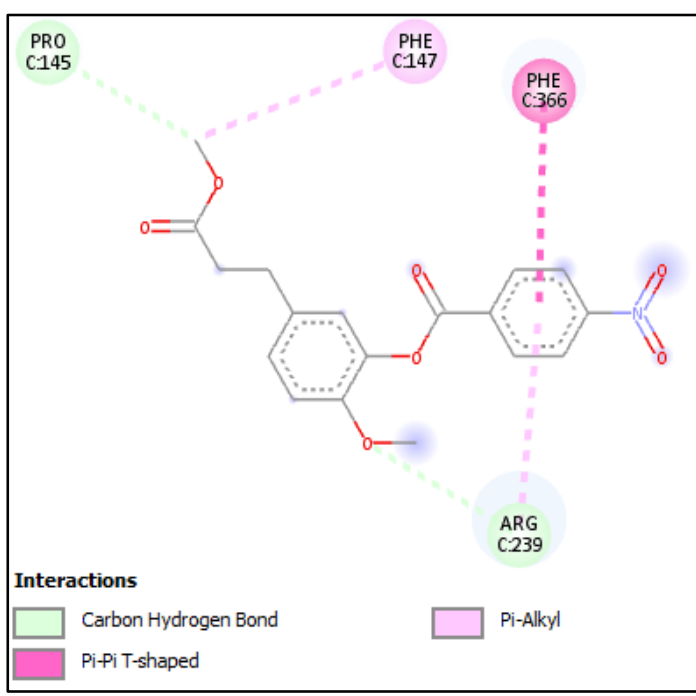

Figure S16. Bonding interactions of active site amino acid with compound-4.

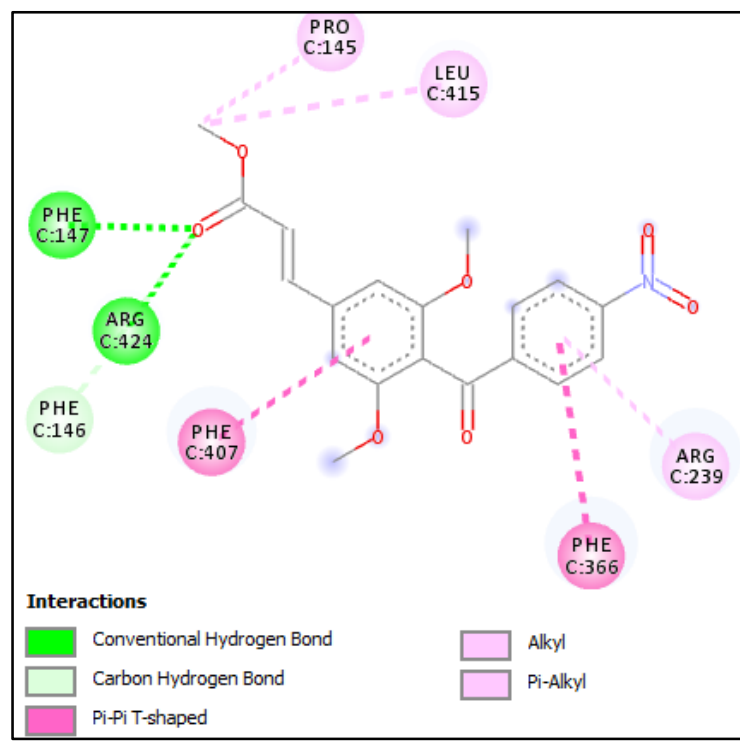

Figure S17. Bonding interactions of active site amino acid with compound-5.

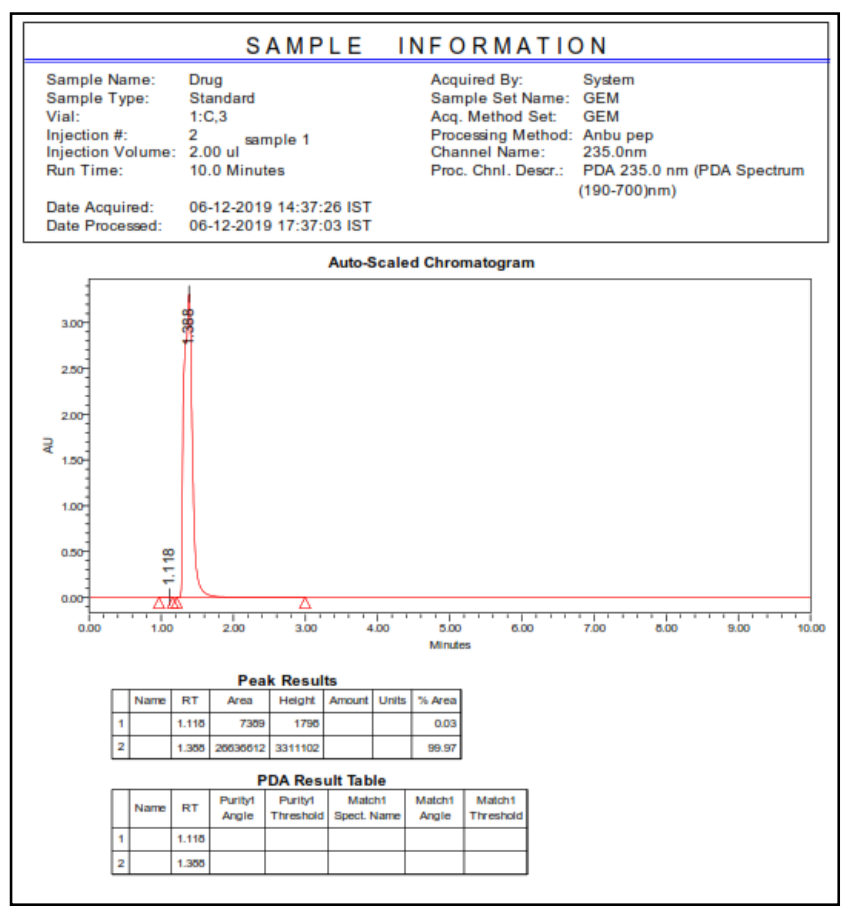

Figure S18. Purity analysis by using UPLC-DAD for Lead compound 1. 


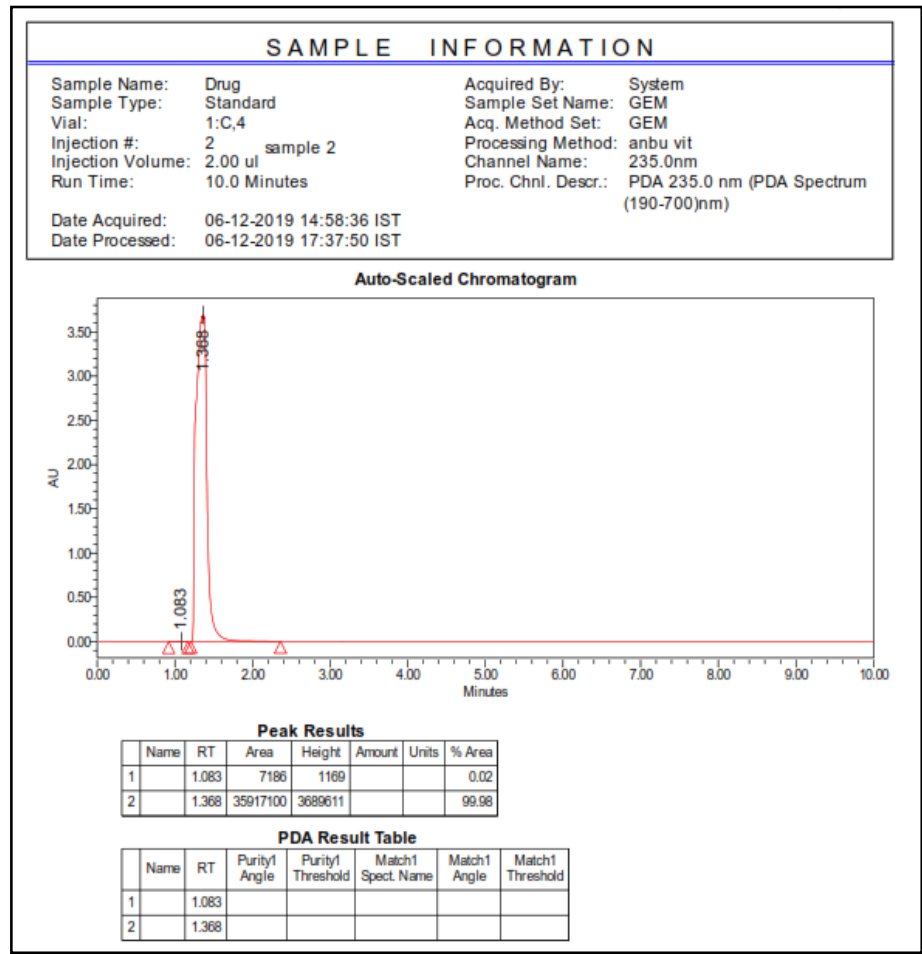

Figure S19. Purity analysis by using UPLC-DAD for Lead compound 2.

Table S1. Experimental details for the crystal structure of compound-1.

\begin{tabular}{|c|c|}
\hline \multicolumn{2}{|c|}{ Crystal data } \\
\hline Chemical formula & ${ }_{14} \mathrm{H}_{9} \mathrm{NO}_{6}$ \\
\hline $\mathrm{M}_{\mathrm{r}}$ & 287.22 \\
\hline Crystal system, space group & Monoclinic, $P 2{ }_{1} / c$ \\
\hline Temperature (K) & 296 \\
\hline$a, b, c(\AA)$ & $8.4263(10), 6.6634(6), 22.572(2)$ \\
\hline$\beta\left(^{\circ}\right)$ & $97.506(6)$ \\
\hline$V\left(\AA^{3}\right)$ & $1256.5(2)$ \\
\hline$Z$ & 4 \\
\hline Radiation type & Mo K $\alpha$ \\
\hline$\mu(\mathrm{mm}-1)$ & 0.12 \\
\hline Crystal size $(\mathrm{mm})$ & $0.25 \times 0.20 \times 0.20$ \\
\hline \multicolumn{2}{|c|}{ Data collections } \\
\hline Diffractometer & Bruker axs kappa apex2 CCD Diffractometer \\
\hline Absorption correction & Multi-scan SADABS (Bruker, 1999) \\
\hline $\mathrm{T}_{\min }, \mathrm{T}_{\max }$ & $0.970,0.976$ \\
\hline $\begin{array}{l}\text { No. of measured, independent and } \\
\text { observed }[\mathrm{I}>2 \sigma(\mathrm{I})] \text { reflections }\end{array}$ & $9777,3126,2005$ \\
\hline $\mathrm{R}_{\text {int }}$ & 0.033 \\
\hline$(\sin \theta / \lambda)_{\max }\left(\AA^{-1}\right)$ & 0.669 \\
\hline \multicolumn{2}{|c|}{ Refinement } \\
\hline $\mathrm{R}\left[\mathrm{F}^{2}>2 \sigma\left(\mathrm{F}^{2}\right)\right], w R\left(\mathrm{~F}^{2}\right), \mathrm{S}$ & $0.048,0.201,0.73$ \\
\hline No. of reflections & 3126 \\
\hline No. of parameters & 191 \\
\hline H-atom treatment & H-atom parameters constrained \\
\hline$\Delta \rho_{\max }, \Delta \rho_{\min }\left(\mathrm{e} \AA^{-3}\right)$ & $0.22,-0.20$ \\
\hline
\end{tabular}

